\section{Pacific Northwest}

National Laboratory

Operated by Battelle for the

U.S. Department of Energy

Estimated Entrainment of Dungeness Crab During Dredging For The Columbia River Channel Improvement Project

\author{
WH Pearson \\ GD Williams \\ JR Skalski
}

December 2002

Prepared for the U.S. Department of Energy

under Contract DE-AC06-76RL01830 


\section{DISCLAIMER}

This report was prepared as an account of work sponsored by an agency of the United States Government. Neither the United States Government nor any agency thereof, nor Battelle Memorial Institute, nor any of their employees, makes any warranty, express or implied, or assumes any legal liability or responsibility for the accuracy, completeness, or usefulness of any information, apparatus, product, or process disclosed, or represents that its use would not infringe privately owned rights. Reference herein to any specific commercial product, process, or service by trade name, trademark, manufacturer, or otherwise does not necessarily constitute or imply its endorsement, recommendation, or favoring by

the United States Government or any agency thereof, or Battelle Memorial Institute. The views and opinions of authors expressed herein do not necessarily state or reflect those of the United States Government or any agency thereof.

\section{PACIFIC NORTHWEST NATIONAL LABORATORY \\ operated by \\ BATTELLE \\ for the \\ UNITED STATES DEPARTMENT OF ENERGY under Contract DE-AC06-76RL01830}

Printed in the United States of America

Available to DOE and DOE contractors from the Office of Scientific and Technical Information,

P.O. Box 62, Oak Ridge, TN 37831-0062;

ph: (865) 576-8401

fax: (865) 576-5728

email: reports@adonis.osti.gov

Available to the public from the National Technical Information Service, U.S. Department of Commerce, 5285 Port Royal Rd., Springfield, VA 22161 ph: (800) 553-6847 fax: (703) 605-6900

email: orders@ntis.fedworld.gov

online ordering: http://www.ntis.gov/ordering.htm 


\title{
ESTIMATED ENTRAINMENT OF DUNGENESS CRAB DURING DREDGING FOR THE COLUMBIA RIVER CHANNEL IMPROVEMENT PROJECT
}

\author{
W. H. Pearson \\ G. D. Williams \\ Marine Sciences Laboratory \\ Pacific Northwest National Laboratory \\ Sequim, Washington \\ J. R. Skalski \\ Columbia Basin Research \\ School of Aqautic and Fishery Sciences \\ University of Washington \\ Seattle, Washington
}

December 2002

\author{
Prepared for \\ Portland District \\ U.S. Army Corps of Engineers \\ Portland, Oregon
}




\begin{abstract}
The studies reported here focus on issues regarding the entrainment of Dungeness crab related to the proposed Columbia River Channel Improvement Project and provide direct measurements of crab entrainment rates at three locations (Desdemona Shoals, Upper Sands, and Miller Sands) from RM4 to RM24 during summer 2002. Entrainment rates of all crab age classes ranged from zero at Miller Sands to 0.224 crabs per cy at Desdemona Shoals in June 2002. The overall entrainment rate at Desdemona Shoals in September was 0.120 crabs per cy. A modified Dredge Impact Model used the summer 2002 entrainment rates to project crab entrainment, adult equivalent loss, and loss to the fishery for the Channel Improvement Project. For construction dredging, estimates of overall adult equivalent loss at age 2+ range from 38,811 to 281,528 crabs. Also for construction dredging, overall losses to the fishery range from 7,252 to 44,342 crabs. For annual maintenance dredging under the Proposed Plan (43' Channel), estimates of adult equivalent loss at age 2+ range from 56,840 crabs in Year 1 to 25,612 crabs in Year 20. Also for maintenance dredging under the Proposed Plan, estimated losses to the fishery range from 8,953 to 4,035 crabs in Year 1 and 20, respectively. The worst-case projected fishery losses represent approximately $1 \%$ of the annual crab landings for the Washington and Oregon region around the Columbia River (5.3 million crabs from 1991 to 2001). To improve the projections, entrainment data from Flavel Bar and Tongue Point are needed. Similiarly, additional sampling days at each upriver location would narrow confidence limits associated with entrainment projections. The literature, analyses of salinity intrusion scenarios, and the summer 2002 site-specific data on entrainment and salinity all indicate that bottom salinity influences crab distribution and entrainment, especially at lower salinities. It is now clear from field measurements of salinity during a period of low river flow (90-150 Kcfs) and high salinity intrusion that entrainment rates are zero where bottom salinity is less than $16 \mathrm{o} / \mathrm{oo}$ most of the time. Further, entrainment rates of age $2+$ and older crab decline in a clear and consistent manner as salinity decreases. More elaboration of the crab distribution- salinity model is needed, especially concerning salinity and the movements of age $1+$ crab.
\end{abstract}




\section{EXECUTIVE SUMMARY}

Proposed dredging during the Columbia River Channel Improvement Project has raised concerns about dredging-related impacts on Dungeness crab in the Columbia River Estuary. The Portland District of the U.S. Army Corps of Engineers engaged the Marine Sciences Laboratory of the U.S. Department of Energy's Pacific Northwest National Laboratory to review the state of knowledge and conduct studies concerning dredgingrelated impacts from entrainment on Dungeness crab from the Columbia River Channel Improvement Project. The studies accomplished three tasks regarding the entrainment of Dungeness crab related to the proposed Channel Improvement Project. The first task provided direct measurements of crab entrainment rates at three locations (Desdemona Shoals, Upper Sands, and Miller Sands) from RM4 to RM24 during summer 2002. The second task used the summer 2002 entrainment data and a modified Dredge Impact Model to project crab entrainment, adult equivalent loss, and loss to the fishery from planned dredging. The third assessed the influence of salinity on crab distribution and entrainment.

Entrainment rates for all age classes of crabs ranged from zero at Miller Sands to 0.224 crabs per cy at Desdemona Shoals in June 2002. The overall entrainment rate at Desdemona Shoals in September was 0.120 crabs per cy.

A modified Dredge Impact Model used the summer 2002 entrainment rates to project crab entrainment, adult equivalent loss, AEL and loss to the fishery associated with construction and maintenance dredging. For construction dredging, estimates of overall AEL at $2+$ range from 38,811 to 281,528 crabs. Also for construction dredging, overall losses to the fishery range from 7,252 to 44,342 crabs. For annual maintenance dredging under the Proposed Plan (43' Channel), estimates of adult equivalent loss at age 2+ range from 56,840 crabs in Year 1 to 25,612 crabs in Year 20. Also for maintenance dredging under the Proposed Plan, estimated losses to the fishery range from 8,953 to 4,035 crabs in Year 1 and 20, respectively. The worst-case projected fishery losses represent approximately $1 \%$ of the annual crab landings for the Washington and Oregon region around the Columbia River (5.3 million crabs from 1991 to 2001). To improve the projections, entrainment data from Flavel Bar and Tongue Point are needed. Additional sampling days at each upriver location would also narrow confidence limits associated with entrainment projections.

The scientific literature, analyses of salinity intrusion scenarios, and the summer 2002 site-specific data on entrainment and salinity all indicate that bottom salinity influences crab distribution and entrainment, especially at lower salinities. It is now clear from field measurements of entrainment rates and salinity during a period of low river flow (90-150 $\mathrm{Kcfs}$ ) and high salinity intrusion that entrainment rates are zero where bottom salinity is less than 16 o/oo most of the time. Further, entrainment rates for $2+$ and older crab decline in a clear and consistent manner as salinity decreases. More elaboration of the crab distribution- salinity model is needed, especially concerning salinity and the movements of $1+$ crab. 


\section{CONTENTS}

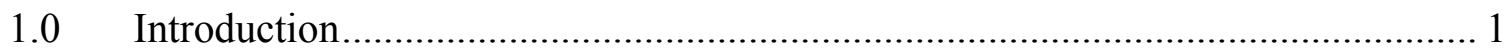

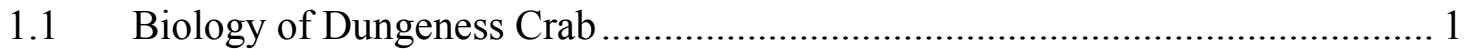

1.2 Salinity Influences on Crab Distribution ......................................................... 2

1.3 Entrainment Measurements and Modeling ........................................................ 3

1.4 Overview of Entrainment Measurements, Projections, and Scenario Analyses. 4

2.0 Materials and Methods.............................................................................. 7

2.1 Methods for Direct Measurements of Entrainment Rates.................................... 7

2.1.1 Summary of Field Activities .............................................................. 7

2.1.2 Statistical Design of Field Sampling......................................................... 7

2.1.3 Methods for Entrainment Observation................................................... 8

2.1.4 Modifications to Standard Sampling Procedures....................................... 9

2.1.5 Calculating Sample Volume ............................................................... 10

2.1.6 Flow Measurements .......................................................................... 11

2.1.7 Calculation of Adult Equivalent Loss and Loss to Fishery for Summer 2002 Dredged Volumes ....................................................................... 12

2.1.8 Statistical Analyses and Calculation of Variance and Confidence Limits 13

2.2 Methods for Projections of Impacts using Modified DIM................................. 18

2.3 Approach for Analysis of Salinity and Crab Distribution ................................ 18

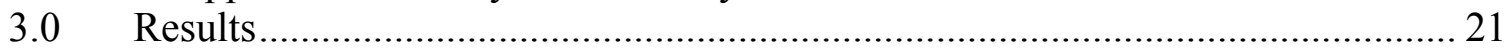

3.1 Direct Measurements of Crab Entrainment ................................................. 21

3.1.1 Entrainment Rates (R)............................................................... 21

3.1.2 DIM Results for Dredged Volumes Accomplished in Summer 2002 ...... 21

3.2 Projections of Crab Entrainment for Channel Improvement Project................ 21

3.3 Analysis of Salinity and Crab Distribution...................................................... 23

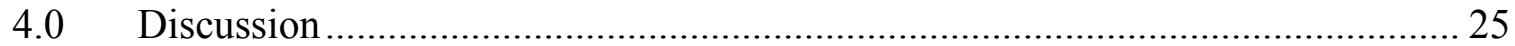

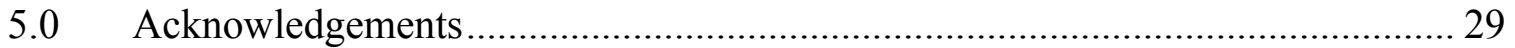

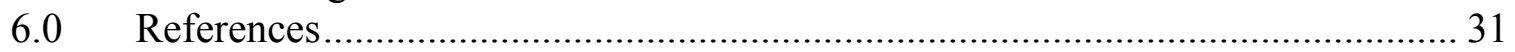

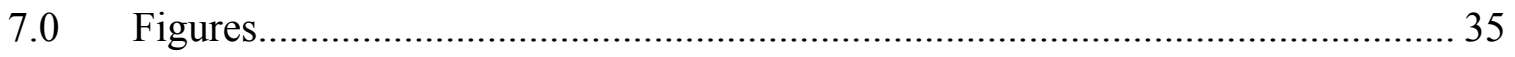

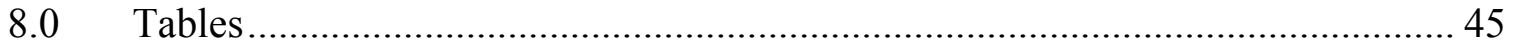

Appendix A - Entrainment Calculations, Summer 2002

Appendix B - Entrainment Projections 


\section{FIGURES}

Figure 1. Crab Density (crab/ha) as a Function of Bottom Salinity. 35

Figure 2. The Relationship Between Crab Density and Bottom Salinity from Regression

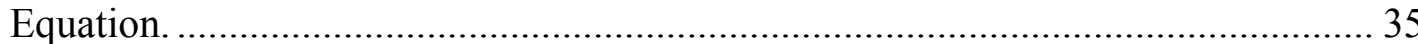

Figure 3. River Flow in the Columbia River Estimated by Combining Flow

Measurements at Bonneville Dam and the Willamette River................................... 36

Figure 4. Bottom Salinity from CORIE Mean Salinity Profile Predicted by ELCIRC

Model for May 21 and September 1, 2002.

Figure 5. The Entrainment Function from the Grays Harbor Dredge Impact Model with

Data from Columbia River Plotted on Same Scale................................................. 38

Figure 6. The Structure of a Modified Model for Estimating Entrainment Impacts on

Dungeness Crab. ............................................................................................... 38

Figure 7. Map of the Study Area with Sampling Areas, Summer 2002 ........................ 39

Figure 8. Diagram of the Piping and Valving on the Corps' Dredge Essayons, Summer

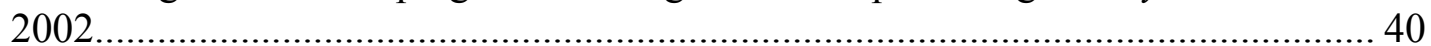

Figure 9. Predicted Crab Density for Six Salinity Intrusion Conditions. ........................ 41

Figure 10. Predicted Crab Density for the Median Low Flow Salinity Intrusion............. 42

Figure 11. Predicted Crab Density Forecasted with the Salinity Crab Density Model and the ELCIRC Forecasts for Bottom Salinity .............................................................. 43 


\section{TABLES}

Table 1. 1+ Crab Densities by Habitat Type................................................................. 45

Table 2. Isohaline Positions in the Columbia River as a Function of River Flow and

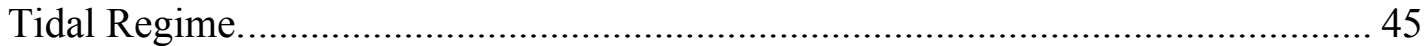

Table 3. Salinity Intrusion as a Function of River Mile in the Columbia River.............. 46

Table 4. Crab Density Determined by Scientific Trawling and Calculated from Dredge

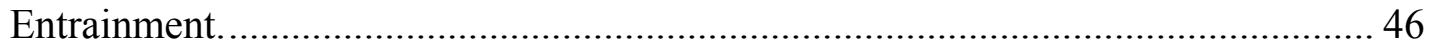

Table 5. Sampling Effort Associated with Various Locations of Crab Entrainment

Sampling on the Dredge Essayons During Summer 2002 .................................... 47

Table 6. Coefficients of Variation of Different Rates of Basket Samples per Dredge

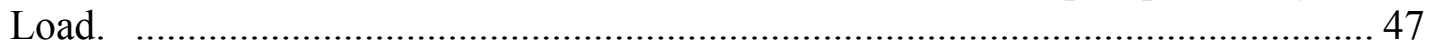

Table 7. Coefficients of Variation of Different Rates of Basket Samples per Dredge Load.

Table 8. Projected Dredge Volumes for Future Construction Dredging (to 40' and from 40 ' to 43') Associated With the Columbia River Channel Improvement Project.... 49

Table 9. Projected Volumes During Year 1 and Year 20 Maintenance Dredging Associated with 40-foot Channel Maintenance (No Action Alternative) and the 43foot Alternative (Proposed Plan).

Table 10. Entrainment Rates from Direct Measurements in Summer 2002 ................... 50

Table 11. Summary of Entrainment Rates (R), Entrainment (E), Adult Equivalent Loss (AEL), and Loss to Fishery (LF) with 95\% Confidence Intervals (CI) for the Dredged Volumes Accomplished During the Summer of 2002. 50

Table 12. Contribution by Age Class to Adult Equivalent Loss (AEL) by Male (M) and Female (F) Crab from Summer 2002 Sampling.

Table 13. Crab AEL and LF Projected for Construction Dredging to $40^{\prime}$...................... 52

Table 14. Crab AEL and LF Projected for Construction Dredging from 40' to 43',...... 53

Table 15. Summary of AEL at 2+ and Losses to Fishery For Construction Dredging Under Worst- and Best-Case Assumptions............................................................. 54

Table 16. Summary of AEL at 2+ and Losses to Fishery For Maintenance Dredging in Year 1 and Year 20 Under Worst-Case Assumptions for Both the "No Action Alternative" and the Proposed Project.

Table 17. Entrainment Rates by Location and the Percentage of Salinity Observations

More Than $32 \mathrm{o} / \mathrm{oo}$ and Less Than $16 \mathrm{o} / \mathrm{oo}$.

Table 18. Results of Regression Analysis Between the Natural Logarithm of the Entrainment Rates and Percentage of Salinity Observations Above $32 \mathrm{o} / \mathrm{oo}$ and Below 16 o/oo. 
xiv 


\subsection{INTRODUCTION}

Proposed dredging of the Columbia River has raised concerns about dredging-related impacts on Dungeness crab in the Columbia River Estuary (CRE). The Portland District of the U.S. Army Corps of Engineers (Corps) engaged the Marine Sciences Laboratory (MSL) of the U.S. Department of Energy's Pacific Northwest National Laboratory (PNNL) to review the state of knowledge and conduct studies concerning dredgingrelated impacts from entrainment on Dungeness crab from the Columbia River Channel Improvement Project. Previously, MSL performed crab studies for the Corps Seattle District during that district's Grays Harbor Navigation Improvement Project (e.g., Pearson 1987, Pearson and Woodruff 1987, Pearson et al. 1987). This document focuses on issues regarding the entrainment of Dungeness crab related to the proposed Columbia River Channel Improvement Project and presents results of field studies conducted from River Mile 3 (RM3) to RM24. A separate report will describe field studies of crab entrainment during 2002 dredging at the Mouth of the Columbia River (MCR).

This document first presents a general background on Dungeness crab biology, the influence of salinity on crab distribution, and the use of a modified Dredge Impact Model (DIM) to estimate entrainment impacts to Dungeness crab for the Columbia River Channel Improvement Project. The document then presents the methods and results from three tasks. The first task was to conduct field studies during the spring and summer of 2002 aboard the Corps' Dredge Essayons to measure crab entrainment rates in some of the areas to be dredged during the proposed project. The second task was to use the 2002 data to estimate crab entrainment impacts for the dredging planned for the Channel Improvement Project. The third task was to postulate scenarios of different salinity regimes and assess their potential influence on crab distribution. The document concludes with a discussion of the results of the three tasks.

\subsection{Biology of Dungeness Crab}

Dungeness crabs use both the nearshore ocean environment and the estuary in their life cycle (Tasto 1983, Armstrong et al. 1987, Rooper et al. 2002). Adult female crabs extrude fertilized eggs in the fall and carry the extruded eggs until hatching in the ocean in late winter. After a 4 to 5 month larval period, the megalopae, the last larval stage, settle to the bottom to become the first crab instar stage (Young of the Year or YOY). In the spring, large numbers of YOY enter the estuaries of the West Coast as late megalopae and perhaps as first true crab. YOY (age $0+$ ) crabs in the estuary grow faster than those in the ocean. Juvenile crabs (age 1+) found in the estuary derive either from $0+$ crabs that over-wintered in the estuary or from 1+ crabs entering the estuary in the summer. To gain perspective, an understanding of the ways in which Dungeness crab use the estuary and how that use may or may not expose them to dredging activity is needed. In spring and summer, $0+$ crabs can be found in the Mouth of the Columbia River (MCR) with annual average densities varying over two orders of magnitude from year to year (Larson 1993). In the Columbia River, Dungeness crabs are found from the MCR to about RM17 (McCabe et al. 1986, 1989). 
It is clear that Dungeness crabs use not only estuarine navigation channels but also other estuarine habitat areas. Age $0+$ crabs are found in intertidal and shallow subtidal areas on substrates with shell hash, eelgrass, or other shelter (Armstrong et al. 1987). After growing to $20-\mathrm{mm}$ carapace width $(\mathrm{CW})$, the $0+$ crabs move to subtidal areas. Age $1+$ crabs use subtidal areas and forage over intertidal areas during high tide. A recent survey of four West Coast estuaries by Rooper et al. (2002) indicates that Dungeness crabs show consistent use of some estuarine habitat types. Side channel habitat near the estuary mouth has highest crab densities, with the lower estuarine main channel and upper estuary having significantly lower densities (Table 1). The characteristics of the preferred lower side channel habitat include shell, macroalgae, shallow depths, high food abundance, temperatures $<18$ degrees $\mathrm{C}$, and salinities above $25 \mathrm{o} / \mathrm{oo}$. The coastal estuaries are estimated to be the basis for $20 \%$ to $40 \%$ of West Coast Dungeness crab fishery production (Armstrong personal communication). The estuaries appear to provide relatively steady contributions to annual crab production while nearshore ocean environments provide crab production that is quite variable from year to year (Armstrong personal communication).

\subsection{Salinity Influences on Crab Distribution}

Salinity has long been suspected to influence the distribution and abundance of Dungeness crabs in west coast estuaries (Tasto 1983, Stevens and Armstrong 1984, McCabe et al. 1986). The notion that low salinity restricts crab distribution is supported by findings that Dungeness crabs are weak osmoregulators and become inactive under low salinity (McGaw et al. 1999). Dungeness crabs were previously thought not to survive at salinities less than $12 \mathrm{o} / \mathrm{oo}$, but recent laboratory studies suggest the ability to survive brief exposure to low salinity. Dungeness crabs show adaptive physiological responses under 6 to $8 \mathrm{~h}$ exposures to 50\% seawater (about $16 \mathrm{o} / \mathrm{oo}$ ) (Brown and Terwillger 1992, 1999, McGaw and McMahon 1996, McGaw et al. 1999). Dungeness crabs can acclimate to continuous exposure to 50\% seawater (about $16 \mathrm{o} / \mathrm{oo}$ ) for 4 days (McGaw and Mahon 1996) and survive 24-h exposure to a salinity of 8 o/oo (McGaw et al. 1999).

Although Dungeness crab can survive brief exposure to low salinities, studies suggest that they do so by being inactive and isolating themselves. Dungeness crabs can detect a 4\% decrease and 5\% increase from ambient salinity (Sugarman et al. 1983) and exhibit behavioral responses to lowered salinity that serve to isolate the osmoregulatory organs from the changing salinity (Sugarman et al. 1983, McGaw et al. 1999). Sugarman et al. (1983) found that the threshold at which $50 \%$ of Dungeness crab close their mouthparts and seal the branchial chamber was 50\% seawater (15.5 o/oo). McGaw et al. (1999) observed that under decreases to 75\%, 50\%, and 25\% seawater (about 24, 16, and 8 $\mathrm{o} / \mathrm{oo}$ ), Dungeness crabs initially showed an immediate increase in movement that lasted less than one hour, after which time the crabs buried and became inactive. Crabs not only became inactive but also retracted the antennules and closed their mouthparts to seal the branchial chamber. At $25 \%$ seawater $(8 \mathrm{o} / \mathrm{oo})$, the antennules were retracted almost $100 \%$ of the time. When the antennules are retracted and the branchial chamber sealed, 
the chemosensory abilities of Dungeness crabs to detect food and other chemical cues are substantially reduced.

Although previous field studies using linear models have found low correlations between crab density and salinity (Stevens and Armstrong 1984, McCabe et al. 1986), our examination of the data of Stevens and Armstrong (1984) using logarithmic models as well as linear models revealed that mean station density for $1+$ and older crabs is logarithmically related to mean bottom salinity (Figure 1). The relationship between salinity and $0+$ crab density appears to be more complex (Figure 1). Regression of logarithmically transformed data of Stevens and Armstrong (1984) for 1+ and older crab yields a significant regression equation ( $p=0.004$ ) with an R-squared of $71 \%$ (Figure 2 ). This equation enables forecasting of crab density from salinity data. For example, predicted crab density at a bottom salinity of $16 \mathrm{o} / \mathrm{oo}$ is less than $1 \%$ of that at $32 \mathrm{o} / \mathrm{oo}$ (Figure 2). It is hypothesized that at bottom salinities above $30 \mathrm{o} / \mathrm{oo}$ crab density is governed by factors other than salinity and that as bottom salinity falls below $30 \mathrm{o} / \mathrm{oo}$ crab density falls logarithmically. Coupling the above salinity-crab density relationship with examination of the complex salinity regime in the Columbia River Estuary enables us to elaborate a conceptual model of the influence of salinity on crab distribution along the South Channel.

Salinity intrusion in the Columbia River is complex and dynamic compared to other estuaries. Two factors contribute to that complexity (Jay and Smith 1990). First, the Columbia River Estuary has extremely large freshwater flows moving through a shallow estuary. Second, the Columbia River Estuary has two channels. Tidal exchange dominates in the North Channel, which is saltier. River flow dominates in the South Channel, which is less salty. River flow levels and neap-spring tide transitions interact to produce the greatest salinity intrusion at neap tides during low flows (Table 2). The interaction of river flow and tidal exchange leads to general declines in bottom salinity at the South Channel as one moves upriver (Table 3). Bottom salinity at and above RM 10 shows substantial variation (Table 3 ).

Examination of the river flow records for 2001/2002 and the CORIE/ELCIRC models enables discernment of recent extremes in salinity intrusion. From October 2001 to October 2002, the combined river flow has varied from a low of $80 \mathrm{Kcfs}$ on October 8 2001 to a high of $433 \mathrm{Kcfs}$ on April 172002 (Figure 3). Predictions of the bottom salinity from the CORIE/ELCIRC Model (http://www.ccalmr.ogi.edu/CORIE/) also reveal that mean bottom salinity decreases moving upriver along the South Channel and that salinity intrusion varies with river flow (Figure 4). Using the CORIE/ELCIRC predictions for CORIE stations greater than $10 \mathrm{~m}$ deep in the South Channel indicates that mean bottom salinities at RM18 would be 10 o/oo for May 212002 with a river flow of $292 \mathrm{Kcfs}$ and 23 o/oo for September 12002 with a river flow of $133 \mathrm{Kcfs}$.

\subsection{Entrainment Measurements and Modeling}

Armstrong and his colleagues (Armstrong et al. 1987, Wainwright et al. 1990, Wainwright et al. 1992) developed the Dredge Impact Model (DIM) for use in the Grays 
Harbor Navigation Improvement Project of the Corps Seattle District. The model evolved over the years and Wainwright et al. (1992) gives a succinct overview of its present form. The DIM takes as inputs the volume of material to be dredged and the density of crab in the environment, applies an entrainment function plus age- and seasonspecific schedules of post-entrainment mortality and natural survival, and yields an estimate of loss to the crab fishery. The actual loss to the fishery is a function of harvest rate. The entrainment function, a key component of the model, was developed from several years of paired observations of the number of crab entrained per cubic yard (cy) dredged versus the crab density (crabs/hectare) determined by scientific trawling. For Grays Harbor, the model was successfully employed to minimize crab impacts through dredge scheduling and to estimate project impacts.

In reviewing the model for use in gaining perspective on crab impacts in the Columbia River, the model structure was found to be generally applicable but the entrainment function and the available data on crab density are not appropriate for use to estimate the effects of dredging on the Columbia River crab population and crab fishery. The entrainment function is probably site specific. The slope of entrainment function in Grays Harbor appears to differ substantially from what the available data from Columbia River indicate (Figure 5). Also, the relationship between crab density from trawls and crab density from dredge entrainment are not the same in Grays Harbor as in the Columbia River (Table 4). Therefore, it would not be appropriate to apply the entrainment function from Grays Harbor to the Columbia River until and unless paired trawling and entrainment measurements provide site-specific data to validate the function. The appropriate site-specific data to evaluate the applicability of the Grays Harbor entrainment function for the Columbia River are not presently available.

Another required input to the DIM is data on crab density by size class and season for the different reaches to be dredged. There is no recent data of this type from the Columbia River. The crab density data from the Columbia River was taken in the 1980's for different purposes, and spatial coverage is sparse for reaches of the Columbia River to be dredged (McCabe et al. 1986, 1989).

To gain perspective on the dredge entrainment impacts using currently available data, a modified DIM (Figure 6) was used in the analysis here. The modified DIM does not depend on the entrainment function from Grays Harbor or trawl data from the Columbia River. The modification employs the entrainment rates directly observed on a Corps dredge in the Columbia River in summer 2002.

\subsection{Overview of Entrainment Measurements, Projections, and Scenario Analyses}

This document reports the results of three tasks:

- Direct measurements of crab entrainment in the field

- Projections of crab entrainment during the dredging planned for the Channel Improvement Project 
- Modeling and scenario analysis of the influence of salinity on crab distribution

In the first task, the scientific team made direct measurements of crab entrainment rates on the Corps' Dredge Essayons, which is equipped with a basket sampler into which a portion of the dredged materials entering the vessel's hopper can be diverted to obtain entrainment samples. During the summer 2002 maintenance dredging, the scientific team sampled at the mouth of the Columbia River (MCR), Desdemona Shoals, Upper Sands, and Miller Sands (Figure 7). Although some results from crab entrainment measurements from the MCR will be discussed here, the MCR studies will be fully detailed in a separate report. The first task also included measurements of fluid flow in the piping to the dredge's basket sampler to determine the factors for sample volumes in calculations of entrainment rates. A modified DIM used the data from the first task to calculate the Adult Equivalent Loss (AEL) and Loss to Fishery (LF) for the volume of materials dredged at each location in summer 2002. The second task used the entrainment rates measured in the summer of 2002 to make projections of crab entrainment using the modified DIM with the dredged volumes planned for the Channel Improvement Project. The third task used a model for the relationship between salinity and crab density to assess relative crab distribution under several scenarios of salinity intrusion in the Columbia River Estuary. The third task included an analysis of the relationship between entrainment rate and bottom salinity using the summer 2002 data. 


\subsection{MATERIALS AND METHODS}

\subsection{Methods for Direct Measurements of Entrainment Rates}

\subsubsection{Summary of Field Activities}

MSL researchers directly measured crab entrainment aboard the Corps' Dredge Essayons in June 2002 and from July through October 2002 when the dredge was engaged in maintenance and operational dredging of the Columbia River (Table 5, Figure 7). This document reports results from sampling at Desdemona Shoals, Upper Sands, and Miller Sands. Detailed results from the sampling in the MCR are reported separately. The Essayons is equipped with a special basket sampler, into which a portion of the dredged materials entering the vessel's hopper can be diverted. To support the calculations of the volume of dredged material sampled by the basket sampler, measurement of the fluid flow in the pipe leading to the basket sampler was conducted in September 2002.

\subsubsection{Statistical Design of Field Sampling}

Before the start of field measurements to determine entrainment rates for Dungeness crab on the Columbia River, the study team developed sampling designs and data analysis plans for the June sampling and for the July to October sampling. To aid in the development of the June sampling design, the Portland District provided previously collected raw data on entrainment rates from the study of Larson (1993). Examination of the Larson (1993) data revealed that the entrainment rates exhibited three major variance components: 1) Day-to-day variability, 2) Load-to-load variability, and 3) Sample-tosample variability within loads. The day-to-day variability was the dominant variance component. Because day-to-day variability dominated, the study team recommended that sampling occur every day of the five days of dredging projected for June 2002. To select appropriate sampling rates to address load-to-load and sample-to-sample variances, coefficients of variation (CV) for various combinations of sampling rates were calculated based on the Larson (1993) data (Table 6). A CV of 0.125 was required for the estimates of entrainment in order to be $95 \%$ confident of being within $\pm 25 \%$ of the true value. To obtain the desired precision for the June 2002 sampling, the study team sampled each day of dredging, selecting half the loads at random and sampling 10 basket samples per load.

To develop the sampling design for the summer 2002 sampling, the results of the June 2002 were examined. Again, the day-to-day variability proved to be the dominant variance component. To select appropriate sampling rates to address load-to-load and sample-to-sample variances for the summer 2002 sampling, coefficients of variation (CV) for various combinations of sampling rates were calculated based on the June 2002 data (Table 7). A CV of 0.125 was required for the estimates of entrainment in order to be $95 \%$ confident of being within $\pm 25 \%$ of the true value. To obtain the desired precision for the summer 2002, the study team sampled each day of dredging, selecting half the loads at random and sampling 3 basket samples per load. 


\subsubsection{Methods for Entrainment Observation}

Researchers conducted crab entrainment studies aboard the Corps' Dredge Essayons in June and from July through October 2002 when the dredge was engaged in maintenance and operational dredging of the Columbia River (Table 5, Figure 7).

The data for estimation of crab entrainment rates were derived from a two-stage sampling scheme. The first stage involved the random sampling of approximately half $(50 \%)$ of the loads collected by the dredge. The second stage involved the random sampling of dredged material within the selected loads. Hence, there were two aspects to the sampling protocol: (1) the random selection of loads, and (2) the random selection of "basket" samples within a load. In June, 9 or 10 basket samples per load were processed. From July to October, 3 basket samples per load were processed. These basket samples were randomly distributed through the period of load collection, which typically took about an hour.

Four sets of data sheets were used to record field data. These included load by load records, sample records, within-load records, and a daily log. The load by load record sheet included a randomly determined schedule constructed to indicate which loads to sample and which not to sample. Total load volumes [cubic yards (cy)] and distances (ft) were recorded onto these sheets for all loads during the duration of the survey, whether sampled or not; this information was obtained from the Essayons' dredge logbook. Sample records were used to record data on individual basket samples taken within a load, including numbers, size, and sex of Dungeness crab entrained. Within-Load records summarized the crab, fish, and mollusks enumerated in each basket sample, along with the volume of the basket sample. Finally, the daily log was used to record pertinent weather conditions, personnel involved, dredge operations, and deviations from normal operating procedures (e.g., repairs, gear modification).

On-deck sampling proceeded according to the following procedures. When ready to sample, the researcher communicated to the vessel bridge via radio to request the use of hydraulics to operate the crab basket sampler and gate valve, and for closure of starboard valve V17 (Figure 8). This configuration allowed the researcher to sample approximately $1 / 2$ the volume of a single drag arm, or $1 / 4$ the total volume of material being loaded by the dredge. The hydraulic gate valve was operated on-deck by the researcher to allow dredged material to flow to the basket sampler. A time interval of approximately 30 seconds (45 seconds at MCR) usually yielded a manageable volume of dredged materials sample. Therefore, standard valve-timing procedures were as follows (time period in parentheses): the valve was opened (from 0 to $11 \mathrm{sec}$ ), valve remained fully open until 15 -second mark (from 11 to $15 \mathrm{sec}$ ), and valve was closed (from 15 to $28 \mathrm{sec}$ ). In all cases, the start time (hh:mm) and time increments (seconds) at which valve closure was initiated and fully closed were recorded. Calculation of sample volumes is explained in a later section of this report.

The basket sampler was then tilted on its side using the second hydraulic valve. The researcher communicated to the bridge that the hydraulics were no longer required and 
received information on the average load rate and ship speed. From July through October, the researcher measured and recorded the temperature $\left({ }^{\circ} \mathrm{C}\right)$ and salinity $(\mathrm{o} / \mathrm{oo})$ of pumped seawater obtained from a catch pan under the cage using a YSI Model 556 multiple probe system (MPS). Finally, the basket sampler was emptied of sample using 5 -gallon buckets, and the sample dumped onto the sorting table.

Researchers sorted whole and parts of living organisms from the sample and identified and enumerated individuals from the following taxa: crab (Cancer magister and other species), shrimp (e.g., Crangon spp.), razor clam, and all fish species. In cases where an animal other than crab was crushed or pieces were collected, the animal was counted only if the head was present (See details below on quantifying crushed crab). The relative abundance of other species (e.g., olive snail, polychaetes) was noted. Total length (length from the tip of the upper jaw to the end of the caudal fin) of fishes was also recorded.

The carapace widths $(\mathrm{CW})$ of all crabs were measured using calipers, and larger crabs were sexed. If $1 / 2$ a carapace was present, this was measured and total $\mathrm{CW}$ was estimated. In cases where a crab was crushed or pieces were collected, we consistently quantified only those crabs for which we collected more than $1 / 2$ carapace, or other matched pieces (e.g., telson, legs, chela, thorax) constituting 1/3 of a crab. When these criteria were not met (e.g., only 2 legs collected), the presence of crab pieces was noted qualitatively ("YES") under the UID (unidentified) crab column on the record sheet. All crabs and crab pieces were dumped into the dredge hopper to minimize duplicate counts on subsequent passes.

Finally, the sediment type (e.g., sand, mud, gravel, shell) and vegetation was noted, the basket sampler was cleaned with a pressure washer, and the process restarted. All data sheets were completed and errors corrected with a single line that was initialed and dated. At the end of each load, researchers reviewed the data sheets for completeness, accuracy, and legibility.

\subsubsection{Modifications to Standard Sampling Procedures}

Slight changes were made to sampling procedures on some dates to maximize data collection during limited sampling windows or mechanical delays. When a mechanical issue prevented sampling of a load scheduled to be sampled, researchers skipped ahead on the random number schedule to the next load to be sampled when operations returned to normal.

There were also situations due to extreme ebb tides or equipment damage when only a single drag arm was used to dredge the channel. In these cases, the volume of dredged material flowing into the vessel was reduced by $1 / 2$. To maintain adequate sample volumes flowing to the basket sampler, the port side valves (V16 and V17) that distributed loads into the hold were closed when sampling occurred (Figure 8). 


\subsubsection{Calculating Sample Volume}

In previous studies, the sample volumes used to estimate crab entrainment were based on full flows of a $66 \mathrm{~cm}$ discharge pipe over a 30-60 second sampling interval (Larson 1993). Coarse estimates of mean flow rates of the discharge pipes were calculated on a load-by-load basis by dividing total pumping time (PT) by total load (cy) (see formulae on p. 7, Larson 1993). Therefore, sample volume was based on flow rate multiplied by sampling interval (total time valve was open).

Observations made during our June sampling effort suggested that procedures for calculating the sample volumes needed to be refined to take into account the depth of fluid in the pipe and the timing of opening and closing the hydraulic gate valves. Flow volumes associated with the dredge hopper discharge pipes were calculated using the following methods.

Computation of the area based on the depth (or degree to which the gate is opened) is based on the following:

The ratio of instantaneous cross-sectional area (Ai) to the half-pipe crosssectional area (Amax) is used to proportionally reduce the full-pipe flow (Qmax) to estimate the instantaneous flow Qi

$\mathrm{Qi}=\mathrm{Ai} / \mathrm{Amax} * \mathrm{Qmax}$

The time series of Qi are time-integrated to get a cumulative volume $\mathrm{V}=$ sum of (Qi $* \mathrm{dt})$ over the 28 second period, or

$\mathrm{V}=\operatorname{sum}$ of $\mathrm{Ai} / \mathrm{Amax} * \mathrm{Qmax} * \mathrm{dt}$.

But Amax, Qmax and dt do not change so that

$\mathrm{V}=\mathrm{dt} * \mathrm{Qmax} / \mathrm{Amax} *$ sum of $\mathrm{Ai}$

The effective sampling interval, Teff $=\mathrm{V} / \mathrm{Qmax}$, or

Teff $=\left(\mathrm{dt}^{*} \mathrm{Qmax} / \mathrm{Amax} *\right.$ sum of Ai $) / \mathrm{Qmax}$

This reduces to Teff $=\mathrm{dt}^{*}($ sum of $\mathrm{Ai}) /$ Amax (hence no functional connection to input Q).

This allows for estimation of Teff with some assumptions:

- After the gate is opened further than half-way, there is no longer an influence on flow

- The non-linear processes are neglected. No friction, no contraction, no acceleration 
- The cross-sectional average velocity is uniform regardless of how far the gate is opened; flow rate is only a function of cross-sectional area available for flow. The average cross-sectional velocity is the same when the pipe is half-full or barely open.

The estimate of effective sampling period (Teff) is based upon the rate the gate valve is opened, the time it stays open, and the rate it is closed; it is not sensitive to overall flow rate. Flows are reduced during the first half of both the gate valve opening and closing intervals. Assuming the pipe is $1 / 2$ full and standard valve-timing procedures (opening from 0 to $11 \mathrm{sec}$, fully open from 11 to $15 \mathrm{sec}$, closing from 15 to $28 \mathrm{sec}$ ), the effective sampling period is 21.4 seconds.

Sample volume was calculated by multiplying effective sampling time $(\mathrm{t})$ by mean load rate $(\mathrm{cy} / \mathrm{t})$ of the discharge pipe feeding the basket sampler. As in Larson (1993), mean load rates of the discharge pipes were calculated on a load-by-load basis by dividing total pumping time (PT) by total load volume in cy (Y). Flow measurements were conducted to clarify what proportion of the total flow (load rate) was diverted into the crab sampler.

\subsubsection{Flow Measurements}

Flow measurements were conducted to verify the assumption that the basket sampler was receiving $25 \%$ of the total load of dredged materials. A FLO-DAR (Model 460 / Data Logger Serial Number: 46000141 / Meter Serial Number: BA0239) open channel, noncontact, radar flow meter was used to estimate velocity, level, and flow of the slurry contained within the pipe. Specifications and accuracy of the instruments were as follows:

Velocity Measurement

Method: Radar

Range: 0.75 to $20 \mathrm{ft} / \mathrm{s}$

Accuracy: $\pm 0.1 \mathrm{ft} / \mathrm{s}( \pm 0.5 \%)$

$\underline{\text { Level Measurement }}$

Method: Ultrasonic

Operating Range: 0.25 to 60 in.

Temperature Compensated

Accuracy: \pm 0.25 in. (1\%)

Flow Measurement

Based on Continuity Equation.

Accuracy: $\pm 5.0 \%$ of reading typical where flow is in a channel with uniform flow conditions.

The sensor was mounted approximately $5 \mathrm{ft}$ downstream of the basket sampler valve, by cutting a hole 6 inches wide by 20 inches long centered on the 26 -inch inside diameter pipe. Flanges were welded on top of the pipe, raising the sensor 5 inches off the top of 
the pipe. Five inches were used as the offset in the data collection for pipe level measurement. The sensor was mounted and connected to data loggers, which in turn were connected to a Dell Inspiron 3800 computer to monitor and record real time measurements.

Initial readings were taken to establish best flow conditions by closing valves 17 starboard and 16 starboard with the basket sampler valve open. This allowed for total starboard dredged materials flow past the sensor. Flow measurements were taken with both port and starboard dredge motors balanced at 250, 275, and $300 \mathrm{rpm}$. The optimum setting was found at $275 \mathrm{rpm}$, with $300 \mathrm{rpm}$ providing too much flow and $250 \mathrm{rpm}$ causing excessive flow pulsing.

Flow measurements were compared between two different piping configurations (total starboard flow vs. normal configuration during crab sampling). To measure total starboard flow, measurement data was logged for approximately 10 to 15 minutes with the dredge motor at $275 \mathrm{rpm}$, the 17 starboard and 16 starboard valves closed, and the basket sampler valve open. To measure flows associated with the typical piping configuration observed during crab sampling, the 16 starboard valve was reopened and measurements logged for approximately 10 to 15 minutes. These flow measurements were then repeated several times over the course of normal dredging operations. When in normal configurations for crab sampling, the pipe was always a minimum of half-full.

Instrument readings indicate that flow coming into the crab basket sampler as a proportion of total flow coming onboard was 0.26 with a $95 \%$ Confidence Interval (CI) from 0.23 to 0.29 . These results provided no evidence to reject the value of 0.25 used by Larson (1993). Therefore, all calculations of sediment load and crab entrainment use factor of 0.25 to correct for the proportion of total flow (load rate) diverted into the basket sampler.

\subsubsection{Calculation of Adult Equivalent Loss and Loss to Fishery for Summer 2002 Dredged Volumes}

To calculate Adult Equivalent Loss (AEL) and Loss to the Fishery (LF) for the dredged volumes accomplished in summer 2002, we used a modified DIM that does not depend

on the entrainment function from Grays Harbor or previous trawl data from the Columbia River. The modification employs the entrainment rates directly measured on the Corps' Dredge Essayons in the Columbia River. The approach (Figure 6) includes the following steps:

1. Use entrainment rates ( $\mathrm{R}$ as crabs per cy) directly measured on the dredge (no need to reference trawl density).

2. Multiply these entrainment rates by the dredged volumes to give the number of crabs entrained ( $E$ as number of crab).

3. Apply the post-entrainment mortality rates from Wainwright et al. (1992) to give immediate losses. 
4. Apply the natural survival rates from Wainwright et al. (1992) to give Adult Equivalent Loss (AEL as number of crab) to midwinter Age 2+. (To obtain the AEL at Age $2+$ for Age 3+ crab, the number of Age 3+ crab was back-calculated to its equivalent at Age $2+$ using the reciprocal of the survival rate.)

5. Apply a survival rate of $45 \%$ to midwinter Age $3+$ (Armstrong et al. 1991) to give AEL at Age 3+.

6. Apply observed sex ratios and a harvest rate of 70\% (Wainwright et al. (1992) to give loss to the fishery (LF as number of crab).

7. Calculate variance and $95 \%$ confidence intervals for $\mathrm{E}, \mathrm{AEL}$, and LF.

8. Compare the loss to the fishery (LF) to the landings (WDFW and ODFW) from the Columbia River Area to give perspective on the estimated impact.

\subsubsection{Statistical Analyses and Calculation of Variance and Confidence Limits}

\section{Estimating Numbers of Entrained Crabs}

In a random sample of loads, crab entrainment densities were estimated from a random sample of dredged material. Hence, the sampling design consists of a two-stage sampling scheme; Stage 1: Random sample of $h$ of $H$ loads and Stage 2: Random sample of dredged materials based $b$ of $B$ basket samples. The estimator of total entrainment for a specific age-class (i.e., size class) of crabs can be expressed as follows:

$$
\hat{E}_{i}=\frac{\sum_{j=1}^{h}\left[\frac{V_{j}}{b_{j}} \sum_{l=1}^{b_{j}} x_{i j l}\right]}{\sum_{j=1}^{h} V_{j}} \cdot \sum_{j=1}^{H} V_{j}
$$

where

$x_{i j l}=$ number of age class $i(i=1, \ldots, A) \mathrm{crabs} / Y^{3}$ measured in the $l$ th basket sample $\left(l=1, \ldots, b_{j}\right)$ in the $j$ th load $(j=1, \ldots, h)$;

$b_{j}=$ number of basket samples observed in the $j$ th load $(j=1, \ldots, h)$;

$h=$ number of loads selected for sampling of crab density;

$H=$ total number of loads at a dredged location;

$V_{j}=$ total volume of dredged materials in the $j$ th load $(j=1, \ldots, h)$.

In turn, $x_{i j l}$ can be expressed in terms of the number of crabs counted and the volume of the $l$ th basket sample of the $j$ th load where

$$
x_{i j l}=\frac{c_{i j l}}{w_{j l}}
$$

where 
$c_{i j l}=$ number of age class $i$ crabs $(i=1, \ldots, A)$ in the $l$ th basket sample $\left(l=1, \ldots, b_{i}\right)$ in the $j$ th load $(j=1, \ldots, h)$;

$w_{j l}=$ volume of the material sampled in the $l$ th basket sample $\left(l=1, \ldots, b_{i}\right)$ in the $j$ th load $(j=1, \ldots, h)$.

As such, the estimator of total crab entrainment for age class $i$ crabs $(i=1, \ldots, A)$ can be expressed as

$$
\hat{E}_{i}=\frac{\sum_{j=1}^{h}\left[V_{j} \frac{\sum_{l=1}^{b_{j}} c_{i j l}}{\sum_{l=1}^{b_{j}} w_{j l}}\right]}{\sum_{j=1}^{h} V_{j}} \cdot \sum_{j=1}^{H} V_{j} .
$$

Estimators (1) and (2) will be the same if sample values $w_{i j}=w_{i}$ are equal within a load. Because sample volumes varied between basket samples, estimator (2) is the preferred estimator of total entrainment.

The variance of $\hat{E}_{i}$ is found by taking the variance in stages. The variance of $\hat{E}_{i}$ (Equation 2) can then be expressed as follows:

$$
\operatorname{Var}\left(\hat{E}_{i} \mid E_{i}\right)=H^{2}\left(1-\frac{h}{H}\right) \frac{\sum_{j=1}^{H}\left(V_{j} R_{i j}-R_{i} V_{j}\right)^{2}}{h(H-1)}+\frac{H}{h} \sum_{j=1}^{H}\left[V_{j}^{2} \cdot \operatorname{Var}\left(\hat{R}_{i j}\right)\right]
$$

where

$R_{i j}=\frac{\sum_{l=1}^{B_{j}} c_{i j l}}{\sum_{l=1}^{B_{j}} w_{j l}}=$ true density of age class $i$ crabs (i.e., $\left.\operatorname{crabs} / Y^{3}\right)$ in the $j$ th load $(j=1, \ldots, H)$

$$
\begin{aligned}
R_{i} & \left.=\frac{\sum_{j=1}^{H} R_{i j} V_{j}}{\sum_{j=1}^{H} V_{j}}=\text { true density of crabs (i.e., crabs } / Y^{3}\right) \text { across all } H \text { levels; } \\
\operatorname{Var}\left(\hat{R}_{i j}\right) & =\frac{\left(1-\frac{b_{j}}{B_{j}}\right)}{b_{j} \bar{w}_{j}} \frac{\sum_{l=1}^{B_{j}}\left(c_{i j l}-R_{i j} w_{j l}\right)^{2}}{\left(B_{j}-1\right)}
\end{aligned}
$$


and where

$$
\begin{aligned}
& \bar{w}_{j}=\frac{\sum_{l=1}^{B_{j}} w_{j l}}{B_{j}}=\text { average volume of basket sample in the } i \text { th load; } \\
& B_{j}=\text { total number of possible basket samples within the } j \text { th load. }
\end{aligned}
$$

Variance formula (3) cannot be used to analyze the field data because it is dependent upon unknown parameter values. Instead, an estimated variance must be calculated and used in confidence interval estimates.

An approximately unbiased variance estimator for $\hat{E}$ can be written as follows:

$$
\operatorname{Var}\left(\hat{E}_{i} \mid E_{i}\right)=H^{2}\left(1-\frac{h}{H}\right) \frac{\sum_{j=1}^{h}\left(V_{j} \hat{R}_{i j}-\hat{R}_{i} V_{j}\right)^{2}}{(h-1)}+\frac{H}{h} \sum_{j=1}^{h} V_{j}^{2} \cdot \operatorname{Var}\left(\hat{R}_{i j}\right)
$$

where

$$
\begin{aligned}
& \hat{R}_{i j}=\frac{\sum_{l=1}^{b_{j}} c_{i j l}}{\sum_{l=1}^{b_{j}} w_{j l}}, \\
& \hat{R}_{i}=\frac{\left[\sum_{j=1}^{h}\left[\frac{\sum_{l=1}^{b_{j}} c_{i j l}}{\sum_{j} w_{j l}}\right]\right.}{\sum_{j=1}^{h} V_{j}}, \\
& \operatorname{Var}\left(\hat{R}_{i j}\right)=\frac{\left(1-\frac{b_{j}}{B_{j}}\right)}{b_{j} \bar{w}_{j}^{2}} \frac{\sum_{l=1}^{b_{j}}\left(c_{i j l}-\hat{R}_{i j} w_{j l}\right)^{2}}{\left(b_{j}-1\right)},
\end{aligned}
$$

which, when $B_{j}$ is very large, simplifies to

$$
\operatorname{Var}\left(\hat{R}_{i j}\right)=\frac{\sum_{l=1}^{b_{j}}\left(c_{i j l}-\hat{R}_{i j} w_{j l}\right)^{2}}{\bar{w}_{j}^{2} b_{j}\left(b_{j}-1\right)},
$$

and where 


$$
\bar{w}_{j}=\frac{\sum_{l=1}^{b_{j}} w_{j l}}{b_{j}} .
$$

Asymptotic $(1-\alpha) 100 \%$ confidence interval estimates for $\hat{E}_{i}$ can be calculated as

$$
\hat{E}_{i} \pm Z_{1-\frac{\alpha}{2}} \sqrt{\operatorname{Var}\left(\hat{E}_{i} \mid E_{i}\right)}
$$

\section{Estimating the Entrainment Rate}

The entrainment rate $\left(R_{i}\right)$ for the $i$ th age class of crabs can be defined by Equation (5) or equivalently as the ratio of the total number of crabs entrained to the total volume of dredged material collected where

$$
R_{i}=\frac{E_{i}}{\sum_{j=1}^{H} V_{j}} .
$$

The entrainment rate $\left(R_{i}\right)$ can be estimated by the ratio

$$
\hat{R}=\frac{\hat{E}_{i}}{\sum_{j=1}^{H} V_{j}}
$$

with associated variance estimator

$$
\operatorname{Var}\left(\hat{R}_{i} \mid R_{i}\right)=\frac{\operatorname{Var}\left(\hat{E}_{i} \mid E_{i}\right)}{\left[\sum_{j=1}^{H} V_{j}\right]^{2}} .
$$

Estimating Adult Equivalent Loss (AEL)

The estimate of adult equivalent loss (AEL) for the Dungeness crab entrainment can be expressed as follows:

$$
\bar{A} E L=\sum_{i=1}^{A} \hat{E}_{i} \cdot \hat{M}_{i} \cdot \hat{S}_{i}
$$

where 
$\hat{E}_{i}=$ estimate of total crabs entrained of age class $i(i=1, \ldots, A)$;

$\hat{M}_{i}=$ estimate of direct mortality associated with the dredging operation on crabs entrained of age class $i(i=1, \ldots, A)$;

$\hat{S}_{i}=$ estimate of the survival probability from age class $i(i=1, \ldots, A)$ to age of interest;

$A=$ number of age classes (i.e., $2+$ or $3+$ ).

Estimates of $\hat{M}_{i}$ and $\hat{S}_{i}$ used in the assessment did not have associated variance estimators. Hence, the contribution of $\operatorname{Var}\left(\hat{M}_{i}\right)$ and $\operatorname{Var}\left(\hat{S}_{i}\right)$ could not be propagated to the overall variance of the AEL estimates. Instead, $\hat{M}_{i}$ and $\hat{S}_{i}$ were treated as known constants when calculating the variance of $A E L$. In which case,

$$
\operatorname{Var}(A E L)=\sum_{i=1}^{A}\left[\operatorname{Var}\left(\hat{E}_{i} \mid E_{i}\right) \cdot \hat{M}_{i}^{2} \cdot \hat{S}_{i}^{2}\right]
$$

Equation (9) will underestimate the true variance of the AEL estimates when $\hat{M}_{i}$ and $\hat{S}_{i}$ are measured with error.

Estimating Loss to Fishery (LF)

The loss to the fishery (LF) of harvestable crabs was estimated by the quantity

$$
\text { EF }=\hat{H} \cdot \sum_{i=1}^{A} \hat{G}_{i} \hat{E}_{i} \hat{M}_{i} \hat{S}_{i}
$$

where

$$
\begin{aligned}
& \hat{G}_{i}=\text { estimated fraction of the } i \text { th age class composed of males, } \\
& \hat{H}=\text { estimated probability of harvesting a male crab in the Dungeness fishery. }
\end{aligned}
$$

Again, assuming the values of $\hat{G}_{i}$ and $\hat{H}$ are known constants, the variance of $Z F$ can be estimated by the formula

$$
\operatorname{Var}(\mathbb{E} F)=\hat{H}^{2} \cdot \sum_{i=1}^{A}\left[\operatorname{Var}\left(\hat{E}_{i} \mid E_{i}\right) \cdot\left(\hat{G}_{i} \cdot \hat{M}_{i} \cdot \hat{S}_{i}\right)^{2}\right] .
$$

Equation (11) will underestimate the true variance of $E F$ when $H$ and $G_{i}$ are measured with error. 


\subsection{Methods for Projections of Impacts using Modified DIM}

Projections of crab AEL and LF associated with future construction dredging were made based on work quantity calculations provided by the USACE Portland District (Table 8). The total dredging prism volumes for each location include two increments: 1) dredging to bring the channel to the 40 -foot depth currently authorized and 2) new work dredging to channel from the 40-depth to the new 43-foot depth. In all cases, projections are compiled by age class (age $2+$ and $3+$ ) and crab sex. These projections were calculated for each of the following upriver bar areas: Desdemona (Lower and Upper combined), Flavel Bar, Upper Sands, and Tongue Point.

For each bar area, we employed the DIM approach outlined above with two modifications. First, entrainment rates ( $R$, as crabs per cy) and sex ratios corresponded to those measured at a particular bar area in 2002. Flavel Bar and Tongue Point were not sampled in 2002. For these two areas, we employed the entrainment rates for sampled locations both upriver and downriver from the areas of interest. Second, entrainment rates $(\mathrm{R})$ were multiplied by the projected dredged volumes (Table 8) to yield the number of crabs entrained (E, as number of crab). The maintenance and deepening projections were run for each of the following cases:

\begin{tabular}{|l|l|}
\hline \multicolumn{1}{|c|}{ Projected Volumes - Upriver Bar Area } & \multicolumn{1}{c|}{$\begin{array}{c}\text { Data Source - Entrainment Rate and Sex } \\
\text { Ratio }\end{array}$} \\
\hline Desdemona & Desdemona, June 2002 \\
\hline Desdemona & Desdemona, Sept 2002 \\
\hline Flavel Bar & Desdemona, June 2002 \\
\hline Flavel Bar & Desdemona, Sept 2002 \\
\hline Flavel Bar & Upper Sands, Sept 2002 \\
\hline Upper Sands & Upper Sands, Sept 2002 \\
\hline Tongue Point & Upper Sands, Sept 2002 \\
\hline Tongue Point & Miller Sands, Oct 2002 \\
\hline Miller Sands & Miller Sands, Oct 2002 \\
\hline
\end{tabular}

Projections of crab AEL and LF associated with future maintenance dredging were made based on work quantity calculations provided by the USACE Portland District (Table 9). DIM runs were made for Year 1 and Year 20 following construction. The maintenance dredging volumes are expected to decline over the 20 years following construction. The worst-case assumptions were used to project entrainment during maintenance dredging.

\subsection{Approach for Analysis of Salinity and Crab Distribution}

To assess the influence of salinity on crab distribution, we applied the salinity-crab density model developed from the Stevens and Armstrong (1984) data (described in Introduction section above) to several scenarios for salinity intrusion into the Columbia River Estuary. The salinity-crab density model was developed for Ages 1+ and older and does not address Age $0+$. The scenarios examined include the following: 
- Six conditions from Jay and Smith (1990) (Table 3) that cover salinity intrusion under low and high river flow and spring and neap tides

- The median under low river flow conditions from Jay and Smith (1990) (Table 3)

- Bottom salinity forecasts from CORIE/ELCIRC for May and September of 2002

The above scenarios were used to develop a series of distributions of bottom salinity by river mile along the South Channel. The salinity-crab density model was used to forecast the relative crab density by river mile for each distribution of bottom salinity by river mile. Predicted crab density is then plotted by river mile.

In addition to the assessment of the scenarios for salinity intrusion, we also regressed the entrainment rates determined for each dredged area during the summer of 2002 against two measures of bottom salinity for the dredged area. For the entrainment rates in June taken at Desdemona Shoals, we used the bottom salinities taken from the bottom CTD deployed at CORIE Station RED2, the station closest to Desdemona Shoals. For all the other areas and times, we used the bottom salinities taken from the dredged materials during the crab entrainment sampling. The two measures of salinity used were the percentage of salinity observations at and above $32 \mathrm{o} / \mathrm{oo}$ and the percentage of salinity observations at and below $16 \mathrm{o} / \mathrm{oo}$. 


\subsection{RESULTS}

\subsection{Direct Measurements of Crab Entrainment}

While the Corps' Dredge Essayons was conducting maintenance dredging in the Columbia River, the scientific team made direct measurements of crab entrainment at Desdemona Shoals in June and September 2002, at Upper Sands in September, and at Miller Sands in October (Table 5). The team sampled 66 of the total of 123 loads dredged at these locations. The total number of basket samples taken at these locations was 348. The data from these samples appears in Appendix A.

\subsubsection{Entrainment Rates (R)}

Dungeness crabs were found in the entrainment samples at Desdemona Shoals and Upper Sands; however, no crab or crab parts were found in the 140 basket samples taken at Miller Sands in October 2002. The total entrainment rates for all age classes varied from zero at Miller Sands to $0.224 \mathrm{crab} / \mathrm{cy}$ at Desdemona Shoals in June 2002 (Table 10). At Desdemona Shoals, June entrainment samples were largely composed of Age 1+ crabs, but by September entrainment samples were dominated by Age $2+$ crabs (Table 10). At Upper Sands, only Age 0+ and Age 1+ crabs were found in the entrainment samples. Other species entrained in moderate numbers included Crangon shrimp, Pacific sand lance (Ammodytes hexapterus), and eulachon (Thaleichthys pacificus) (Appendix A5).

\subsubsection{DIM Results for Dredged Volumes Accomplished in Summer 2002}

The results of applying the DIM for dredged volumes accomplished during summer 2002 are summarized in Table 11 and Table 12, and detailed in Appendix A. The lowest dredge impacts were observed at Miller Sands, and the highest at Desdemona Shoals in June. Crab AEL at Age 2+ ranged from zero at Miller Sands, to 6,314 crabs (95\% Confidence Interval (CI) of 5,403 to 7,225 crabs) at Desdemona Shoals in June 2002. Loss to the fishery ranged from zero at Miller Sands, to 1,194 crabs (95\% CI of 1,004 to 1,384 crabs) at Desdemona in June 2002. The AEL at Age 2+ and the loss to the fishery at Upper Sands were less than 1\% of the AEL and LF at Desdemona Shoals in June 2002.

\subsection{Projections of Crab Entrainment for Channel Improvement Project}

The Channel Improvement Project involves planned construction dredging at four locations between RM3 and RM20: Desdemona Shoals, Flavel Bar, Upper Sands, and Tongue Point (Tables 8 and 9). Crab entrainment, AEL at 2+, AEL at 3+, and loss to fishery (LF) were projected for two construction increments (dredging to $40^{\prime}$ and from 40 to 43') and four annual maintenance scenarios (40' Channel Maintenance under the No Action Alternative in Year 1 and Year 20; 43'Channel Alternative Maintenance under the Proposed Plan in Year 1 and Year 20) for these locations using the entrainment rates directly measured in the summer of 2002. In total, nine sets of projections were run (Appendix B). Two sets of projections were conducted for Desdemona Shoals based on 
June and September 2002 entrainment data, respectively. Sets of projections were also run for Upper Sands and Miller Sands. Three sets of projections for Flavel Bar and two for Tongue Point were made using the entrainment rates measured from the nearest areas up and down river of the area of interest.

The results of construction projections are summarized in Table 13 (dredging to 40') and Table 14 (dredging from 40' to 43'), and detailed in Appendix B. In general, the lowest projected AEL at age $2+$ was observed at Tongue Point, whereas the highest projected AEL at 2+ were observed at Flavel Bar. Construction projections for AEL at Age 2+ range from zero at Tongue Point using the Miller Sands entrainment rates, to 117,834 crabs $(95 \%$ CI of 71,066 to 164,602 crabs) at Flavel Bar using the September Desdemona Shoals entrainment rates. Similarly, loss to the fishery from construction ranged from zero at Tongue Point using the Miller Sands entrainment rates, to 18,559 crabs $(95 \%$ CI of 11,193 to 25,925 crabs) at Flavel Bar using the September Desdemona entrainment rates.

The worst-case (highest AEL and LF) and best-case (lowest AEL and LF) projections during construction dredging are summarized by location in Table 15. Estimated total AEL at 2+ ranges from 20,772 to 114,640 crabs during construction dredging to $40^{\text {' }}$ (Table 15). Most of this loss would occur in Desdemona Shoals under either the best or worst case assumption. Estimated total AEL at 2+ ranges from 18,039 to 166,888 crabs during construction dredging from 40' to 43'. Flavel Bar contributes the greatest portion of this loss $(117,834$ crabs) under the worst-case assumption, whereas Desdemona Shoals contributes the greatest portion $(16,023 \mathrm{crab})$ using the best-case assumption. Projected overall AEL at 2+ from both increments of construction dredging ranges from 38,811 to 281,528 crabs. Overall projected losses to the fishery from construction dredging range from 7,252 to 44,342 crabs.

Projections of crab AEL at 2+ and LF under annual maintenance dredging for the No Action Alternative (40' Channel) and the Proposed Plan (43' Channel) are summarized by location and year in Table 16. These values reflect the following worst-case (highest loss) projections: Flavel Bar (Entrainment rate [R] from Desdemona September), Desdemona ( $\mathrm{R}$ from Desdemona September), Tongue Point ( $\mathrm{R}$ from Upper Sands), and Upper Sands (R from Upper Sands). Projected losses from maintenance dredging generally mirror estimated dredging volumes, which are predicted to be higher in Year 1 than in Year 20.

For maintenance dredging under the No Action Alternative (40' Channel), estimated total AEL at 2+ ranges from 44,643 crabs in Year 1 to 25,503 crabs in Year 20 (Table 16). Most of this loss is predicted to occur at Flavel Bar in both Year 1 (40,295 crab) and Year 20 (21,155 crab). For maintenance dredging under the Proposed Plan (43' Channel), the estimated total AEL at 2+ ranges from 56,840 crabs in Year 1 to 25,612 crabs in Year 20. Again, Flavel Bar contributes the greatest portion of this loss in both Year $1(50,369$ crabs) and Year 20 (21,155 crabs). For maintenance dredging under the Proposed Plan (43' Channel), projected losses to the fishery are 8,953 and 4,035 in Year 1 and 20, respectively. 


\subsection{Analysis of Salinity and Crab Distribution}

Using the Jay and Smith (1990) conditions, modeling indicates that the highest crab densities are seaward of RM10. Of the six conditions modeled (Table 3), the highest crab densities are seaward of RM5 with moderate crab densities at RM10 under maximum intrusion for two conditions: 1) low river flow and spring tides, and 2) high river flow and spring tides (Figure 9). The condition showing the furthest upriver extent of crab densities is for maximum intrusion under low river flow and neap tides. Under this condition for furthest upstream extent of crab densities, predicted crab density at RM18 is about $8 \%$ of that at RM0. For the field salinity measurements of Jay and Smith (1990), the low river flows ranged from 120 to $150 \mathrm{Kcfs}$, and the high river flows, from 535 to 570 Kcfs. Under the median of the low flow conditions of the Jay and Smith (1990) conditions, crab densities predicted at and above RM10 are less than $1 \%$ of those predicted at RM0 (Figure 10).

From October 2001 to October 2002, the river flow ranged from slightly less than 100 Kcfs to a brief peak of about $430 \mathrm{Kcfs}$ (Figure 3 ). Plots of the bottom salinities forecast by the CORIE/ELCIRC model for May 21, 2002 and September 1, 2002 (Figure 11) show that salinity intrusion was greater under a river flow of $133 \mathrm{Kcfs}$ in September than under a river flow of $292 \mathrm{Kcfs}$ in May. For the May flow, predicted crab density at RM13 was less than 1\% of that predicted at RM1 (Figure 11). For the September flow, predicted crab density at RM13 was about $9 \%$ of that at RM1.

Site-specific data from the Columbia River in summer 2002 support the concept that salinity influences crab distribution. In summer 2002, entrainment rates fell as the bottom waters became fresher (Table 15). At Miller Sands, where bottom salinities were less than $16 \mathrm{o} / \mathrm{oo}$ for $100 \%$ of the salinity measurements, no crab or crab parts were entrained in any of the 140 basket samples. In the MCR, where bottom salinities were above 28 o/oo for $98 \%$ of salinity measurements, crabs were consistently entrained over the course of the summer sampling. For all age classes, 1+ and older, regression analysis showed that the natural logarithms of the entrainment rate for each dredged area were significantly related to the percentage of salinity observations less than $16 \mathrm{o} / \mathrm{oo}$ but not to the percentage of salinity above $32 \mathrm{o} / \mathrm{oo}$ (Table 16). For age $1+$ crabs alone, the natural logarithms of the entrainment rates were not significantly related to either measure of salinity. At Desdemona Shoals, age $1+$ crabs had a higher entrainment rate $(\mathrm{R}=0.193$ $\mathrm{crab} / \mathrm{cy})$ in June 2002 when bottom waters were fresher (16\% of salinity observations less than $16 \mathrm{o} / \mathrm{oo})$ than the rate $(\mathrm{R}=0.022 \mathrm{crab} / \mathrm{cy})$ in September when the bottom waters were saltier ( $0 \%$ of the salinity observations less than $16 \mathrm{o} / \mathrm{oo})$. For age $2+$ and older, regression analysis revealed that the natural logarithms of the entrainment rates were significantly related to both the percentage of salinity observations above $32 \mathrm{o} / \mathrm{oo}$ and the percentage below $16 \mathrm{o} / \mathrm{oo}$ (Table 16). The parameter explained explaining the highest percentage of the variation in regressions was the percentage of salinity observations less than $16 \mathrm{o} / \mathrm{oo}$. 


\subsection{DISCUSSION}

The entrainment rates reported here constitute a major step in quantifying crab entrainment in the Columbia River Estuary above RM3. The previous measurements of entrainment rates in the Columbia River were much more limited. For example, entrainment rates measured by Larson (1993) were restricted to the Mouth of the Columbia River, whereas the pilot sampling by PIE in spring 2002 at Desdemona Shoals was restricted to one day.

Entrainment rates (in areas where crab occurred) measured in this report were from the middle of the range to the low end of those reported in previous studies. Entrainment rates for all age classes reported here for the summer of 2002 ranged from 0.020 to 0.224 crabs per cy for locations above RM4 and below RM20 (Table 9). In comparison, Larson (1993) reported annual average entrainment rates in the MCR (below RM3) ranging from 0.32 to 10.78 crabs per cy for $0+$ crab and from 0.03 to 0.18 crabs per cy for $1+$ and older crab. Other studies in the Grays Harbor estuary reported entrainment rates that ranged from 0.03 to 0.5 crabs per cy (Wainwright et al. 1992). The rates of Wainwright et al. (1992) were derived from 14 surveys of 2 to 3 days each conducted over several years.

It should be noted that the entrainment rates reported and used here are based on sampling conducted during the summer months of a single year. Crab abundance in the Columbia River and other estuaries is know to vary by season, and from year to year within a season. For example, we attribute the relatively few $0+$ crab found in the summer 2002 samples to not having sampled in May and early June when large numbers of 0+ crab enter the lower estuary (McCabe et al. 1986, 1989; Larson 1993). McCabe et al. (1989) found that the density of $0+$ crab at Flavel Bar had declined substantially (0 to $10 \mathrm{crabs} / \mathrm{ha}$ ) by July in each of the four years they conducted their studies.

Entrainment rates also may change at a particular location over time, based on crab movement patterns that are likely influenced by season, salinity, population structure, and behavioral interactions. For example, the entrainment rate for all age classes at Desdemona Shoals declined from 0.224 crabs per cy in June, to 0.120 crabs per cy in September (Table 9). Age 1+ crab contributed the most to the higher June entrainment rate, while the entrainment rate for $1+$ crab in September was about $11 \%$ of that in June. Similarly, McCabe et al. (1989) found 1+ crab (their Size Class II) at Flavel Bar to have a 4-year average density of 517 crabs/ha in June and 35 crabs/ha in September (about 6\% of the June average). This change in age $1+$ crab entrainment rates at Desdemona Shoals could be related to seasonal migration patterns. Armstrong et al. (1987) found that some component of the age 1+ crab population entered the Grays Harbor Estuary from the ocean in the spring, and migrated out of the estuary to the ocean in the fall. Differences in the salinity regime in the Columbia River Estuary from June to September may also have influenced crab distribution. From late May through early July 2002, river flows ranged between 300 and $400 \mathrm{Kcfs}$; in September, river flows ranged from 90 to $150 \mathrm{Kcfs}$. Avoidance of low salinity water at high river flows may have caused the $1+\mathrm{crab}$ to move from the shallower areas to the deeper and saltier waters of the channels. 
The following projections, listed with entrainment source data in parentheses, represented worst-case losses (AEL at 2+) for the combination of both construction dredging increments: Flavel Bar (Desdemona September), Desdemona (Desdemona September), Upper Sands (Upper Sands), and Tongue Point (Upper Sands). Best-case losses were as follows: Desdemona (Desdemona June), Flavel Bar (Upper Sands), Upper Sands (Upper Sands), Tongue Point (Miller Sands). It should be noted that although Desdemona June total entrainment values are higher, Desdemona September data have a greater source of impact on projected adult losses because samples were dominated by older crabs. For locations not sampled in 2002 (Flavel Bar and Tongue Point) entrainment rates for sampled locations downriver yielded the highest projected losses (worst case); conversely, entrainment rates from adjacent upriver locations yielded lowest projected losses (best case).

Projections for crab entrainment during the Channel Improvement Project have some assumptions that need to be noted. First, the projections were based on currently planned dredge volumes. These projections will need to be changed if the dredged volumes at the planned locations are modified; actual impacts will depend on the volumes finally dredged during the project. Second, crab entrainment data were not collected at Flavel Bar and Tongue Point, and we attempted to bound the projected range of likely impacts by using data collected in adjacent areas. As a result, projections for Flavel Bar are probably overestimated by using data from Desdemona Shoals and underestimated by using data from Upper Sands. We recommend a high priority be given to obtaining entrainment data from upriver areas (Flavel Bar and Tongue Point) not sampled during 2002. Third, location specific entrainment data encompassed a range of effort that was generally dictated by the dredge schedule. In general, the coefficient of variation (CV) falls as sampling effort (e.g., number of sampling days) increases. More sampling days at each upriver location would narrow the confidence limits associated with entrainment projections. Finally, the estimates made in this paper are constrained by many of the same assumptions noted by Armstrong et al. (1987) and Wainwright et al. (1992), for estimates of crab size-at-age, mortality, survival, and exploitation rates.

The crab loss projections in this paper fall within the range reported by previous authors for Grays Harbor (Armstrong et al. 1987, Wainwright et al. 1992). Our estimates reflect a loss of approximately 38,811 to 281,528 age $2+$ crabs for the combined construction increments, and of 25,612 to 56,840 age 2+ crabs for annual maintenance under the Proposed Plan (43' Channel). These estimates correspond to fishery losses of approximately 7,252 to 44,342 age $3+$ male crabs for the combined construction increments, and of 4,035 to 8,953 age 3+ male crabs for annual maintenance under the Proposed Plan. Worst-case projected fishery losses represent about $1 \%$ of the annual crab landings for the Washington and Oregon region around the Columbia River (5.3 million crabs from 1991 to 2001). In the hypothetical Grays Harbor confined disposal scenario presented by Wainwright et al. (1992), estimated losses of age $2+$ crabs ranged from 166,000 to 587,000 crabs. Wainwright et al.'s (1992) estimates correspond to fishery losses from 37,000 to 134,000 age $3+$ male crabs, which represented $1 \%$ to $4 \%$ of the average annual catch by the Washington coast fishery. 
The scientific literature, scenario analyses, and the summer 2002 site-specific data on entrainment and salinity all indicate that bottom salinity influences crab distribution, especially at lower salinities. It is now clear from field measurements of entrainment rates and salinity during a period of low river flow (90-150 Kcfs) and high salinity intrusion that entrainment rates are zero where bottom salinity is less than $16 \mathrm{o} / \mathrm{oo}$ most of the time. This result is supported by physiological studies that indicate that Dungeness crab are stressed and become inactive at 16 o/oo. Also, McCabe et al. (1986) found no crab at stations with average bottom salinities of 3.5 and $8 \mathrm{o} / \mathrm{oo}$ (above RM18) and found crab only "infrequently" at stations with average bottom salinities of 15.9 (about RM14) and 20.2 (about RM12). The model for the influence of salinity on crab distribution and entrainment needs further development. The relationship of the $1+$ crab to salinity appears to be more complex than that for the $2+$ and older crabs, for which the regressions between the logarithm of crab entrainment rate and the percentage of salinity observations below $16 \mathrm{o} / \mathrm{oo}$ were significant and explained a high degree (91\%) of the variation. 


\subsection{ACKNOWLEDGEMENTS}

This study would not have been possible without the assistance and sacrifice of a number of individuals. First of all, we would like to gratefully acknowledge the contributions of Captain Nyberg, Captain Henry, and each crew member aboard the USACE Dredge Essayons. Their accommodating attitude, gracious hospitality, and innovative problem solving provided a safe, enjoyable working atmosphere that enabled us meet all of our project goals. We would also like to thank the Battelle field crew: Mike Anderson, Gary Dennis, Heida Diefenderfer, Nathan Evans, Nancy Kohn, Lohna O’Rourke, John Southard, and Jeff Ward, who were adaptable to an ever-changing dredge schedule and often worked under difficult field conditions. The quality of this data is a tribute to their hard work and dedication. We would also like to thank Tim Burge (USACE engineer) for assistance in conducting flow velocity measurements, as well as Jim Calnon (USACE engineer), Rachel Gumpenberger (USACE engineer), and Calvin Hsieh (USACE engineer) for sampling efforts during the June field trials. This work was supported by the USACE Portland District. Mr. Kim Larson was the USACE Technical Representative; Ms. Laura Hicks was the USACE Project Manager for the Channel Improvement Project. 


\subsection{REFERENCES}

Armstrong, David A., T. C. Wainwright, J. Orensanz, P. A. Dinnel, and B. R. Dumbauld. 1987. Model of Dredging Impact on Dungeness Crab in Grays Harbor, Washington. Fisheries Research Institute, University of Washington, School of Fisheries; FRI-UW-8702.

Brown, A.C., and N.B. Terwilliger. 1992. Developmental changes in ionic and osmotic regulation in the Dungeness crab, Cancer magister. Biological Bulletin 182:270-277.

Brown, A.C., and N.B. Terwilliger. 1999. Developmental changes in oxygen uptake in Cancer magister (Dana) in response to changes in salinity and temperature. Journal of Experimental Marine Biology and Ecology 241:179-192.

Jay, D.A., and J.D. Smith. 1990. Circulation, density distribution, and neap-spring transitions in the Columbia River Estuary, pp. 81-112. In: M.V. Angel and R.L. Smith (eds). Columbia River: Estuarine System. Progress in Oceanography 25 (1-4). Pergamon Press. New York.

Larson, Kim W. 1993. Entrainment of Dungeness Crabs by Hopper Dredge at The Mouth of The Columbia River, OR and WA. U.S. Army Corps of Engineers, Portland District; 1993.

McCabe, G. T. Jr., and R. J. McConnell. 1989. Abundance and size-class structure of Dungeness crabs in our near frequently dredged areas in the Columbia River estuary. National Marine Fisheries Service, 2725 Montlake Boulevard East, Seattle, WA. Report to Portland District, U.S. Army Corps of Engineers, P.O. Box 2946, Portland, OR 97208-2946. 22 pp.

McCabe, G. T. Jr., R. L. Emmett, T. C. Coley, and R. J. McConnell. 1986. Distribution, abundance, and size-class structure of Dungeness crabs in the Columbia River Estuary. National Marine Fisheries Service, 2725 Montlake Boulevard East, Seattle, WA. Final Report to Portland District, U.S. Army Corps of Engineers, Contract DACW57-84-F-0178. 57 pp.

McGaw, I.J., and B.R. McMahon. 1996. Cardiovascular responses resulting from variation in external salinity in the Dungeness crab, Cancer magister. Physiological Zoology. 69:1384-1401. 
McGaw, I.J., C.L. Reiber, and J.A. Guadagnoli. 1999. Behavioral physiology of four crab species in low salinity. Biological Bulletin 196:163-176.

Pearson, W.H. and D.L. Woodruff. 1987. Effects of Proposed Dredged Materials from Grays Harbor on Bait Odor Response in Dungeness Crab (Cancer magister). PNL-6436. Prepared for the U.S. Army Corps of Engineers, Seattle District, by Battelle/Marine Sciences Laboratory, Sequim, Washington. Published by Pacific Northwest Laboratory, Richland, Washington.

Pearson, W.H., D.L. Woodruff, P. Wilkinson, J.S. Young, H.L. McCartney, and D.C. Klopfer. 1987. Data Report for the 1984-1985 Ocean Surveys to Investigate Potential Ocean Disposal Sites off Grays Harbor, Washington. PNL-6280. Prepared for the U.S. Army Corps of Engineers, Seattle District, by Battelle/Marine Sciences Laboratory, Sequim, Washington. Published by Pacific Northwest Laboratory, Richland, Washington.

Pearson, W.H. 1987. Conclusions of the Third Meeting of the Crab Study Panel Examining Issues Related to Dungeness Crab for the Grays Harbor Navigation Improvement Project. PNL-6257. Prepared for the U.S. Army Corps of Engineers, Seattle District, by Battelle/Marine Sciences Laboratory, Sequim, Washington.

Rooper, C.N, D.A. Armstrong, and D.R. Gunderson. 2002. Habitat Use by Juvenile Dungeness Crab in Coastal Nursery Estuaries. Crabs in Cold Water Regions: Biology, Management, and Economics. Alaska Sea Grant College Program, Publication AK-SG-02-01. pp. 609-629.

Stevens, B.G, and D.A. Armstrong. 1984. Distribution, abundance, and growth of juvenile Dungeness crabs, Cancer magister, in Grays Harbor estuary, Washington. Fishery Bulletin 82:469-483.

Sugarman, P.C., W.H. Pearson, and D.L. Woodruff. 1983. Salinity Detection and Associated Behavior in the Dungeness Crab, Cancer magister. Estuaries $6: 380-385$.

Tasto, R.N. 1983. Juvenile Dungeness crab, Cancer magister, studies in the San Francisco Bay area, pp. 135-154. In: P.W. Wild and R.N Tasto (eds) Life History, Environment and Mariculture Studies of the Dungeness Crab, Cancer magister, with Emphasis on the Central California Fishery Resource. Fish Bulletin 172 of the Department of Fish and Game, State of California. 
Wainwright, Tom C.; K.A. McGraw, D.A. Armstrong, B.R. Dumbauld, and L.L. Conquest. 1990. Impact of Dredging on Dungeness crab, Cancer magister, in Grays Harbor, Washington, during August 1989. Fisheries Research Institute, University of Washington, School of Fisheries; 1990; FRI-UW9005 .

Wainwright, T. C., D. A. Armstrong, P. A. Dinnel, J. M. Orensanz, and K. A. McGraw. 1992. Predicting the effects of dredging on a crab population: An equivalent adult loss approach. Fishery Bulletin 90:171-182. 


\subsection{FIGURES}

Figure 1. Crab Density (crab/ha) as a Function of Bottom Salinity. Plotted from Data of Stevens and Armstrong (1984). Note logarithmic scale.

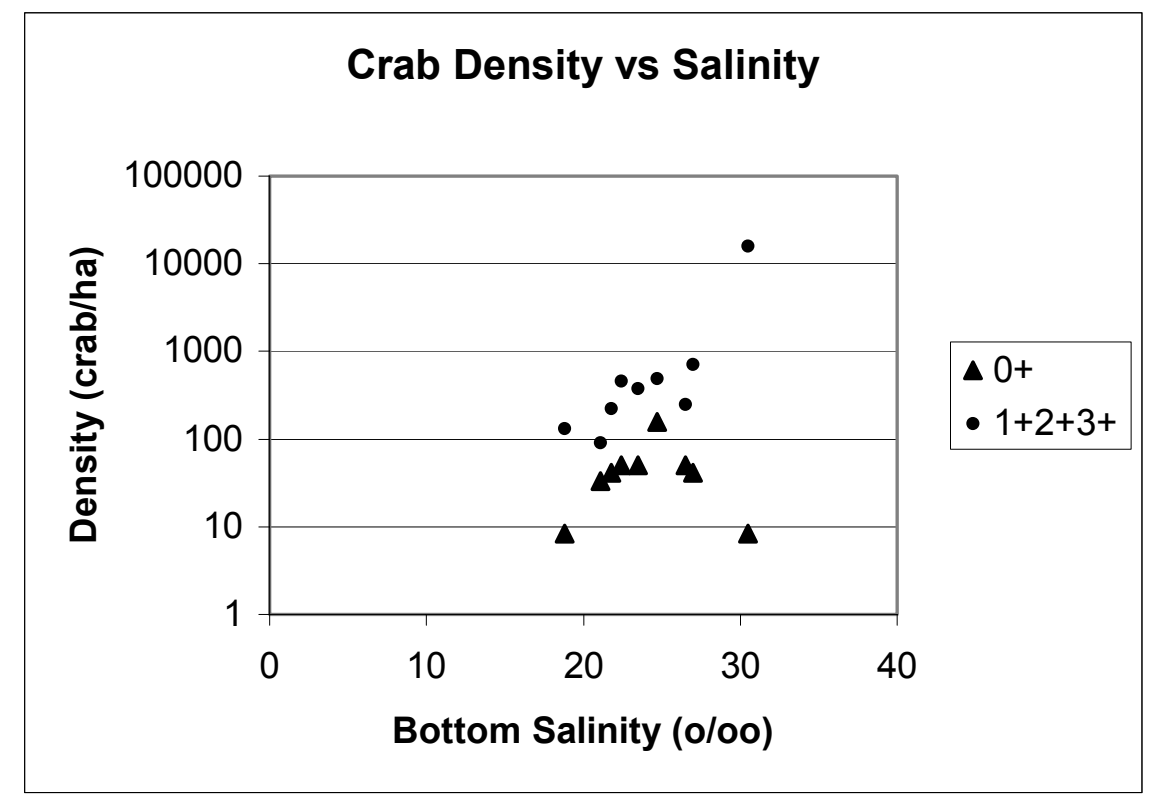

Figure 2. The Relationship Between Crab Density and Bottom Salinity from Regression Equation. Based on Data of Stevens and Armstrong (1984).

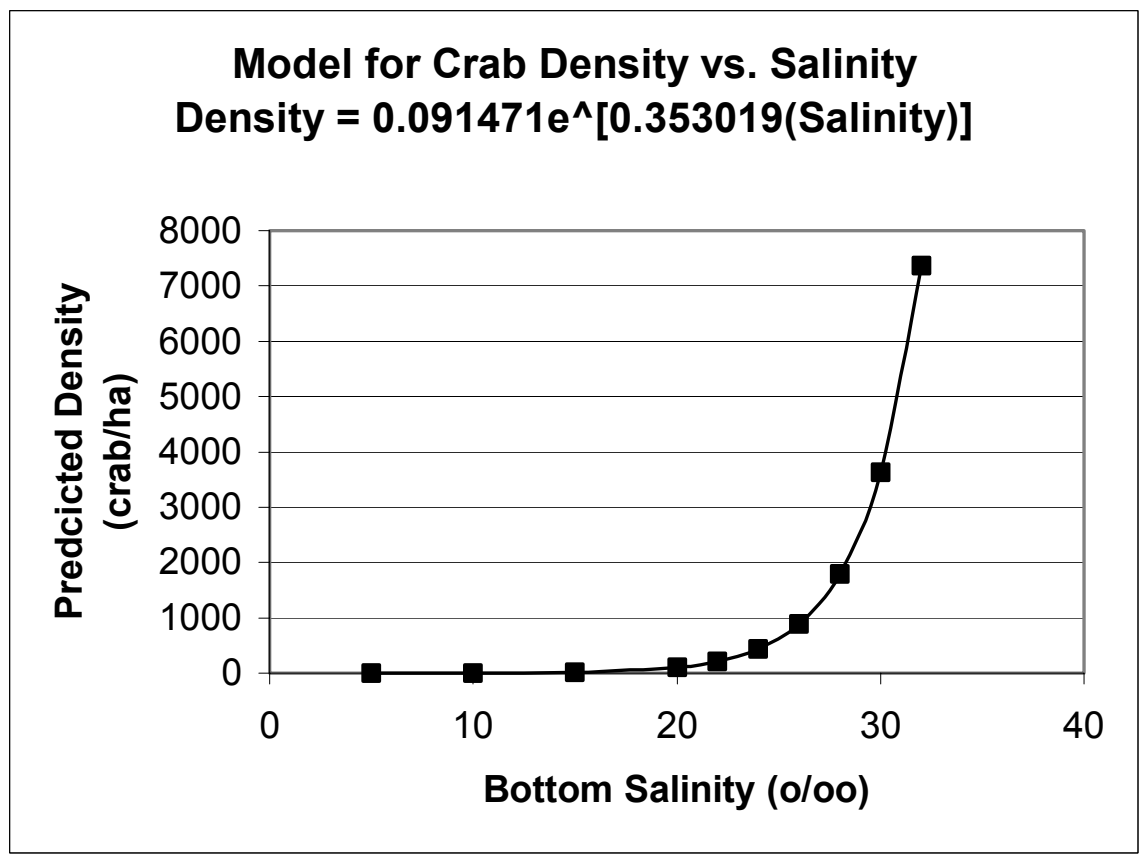



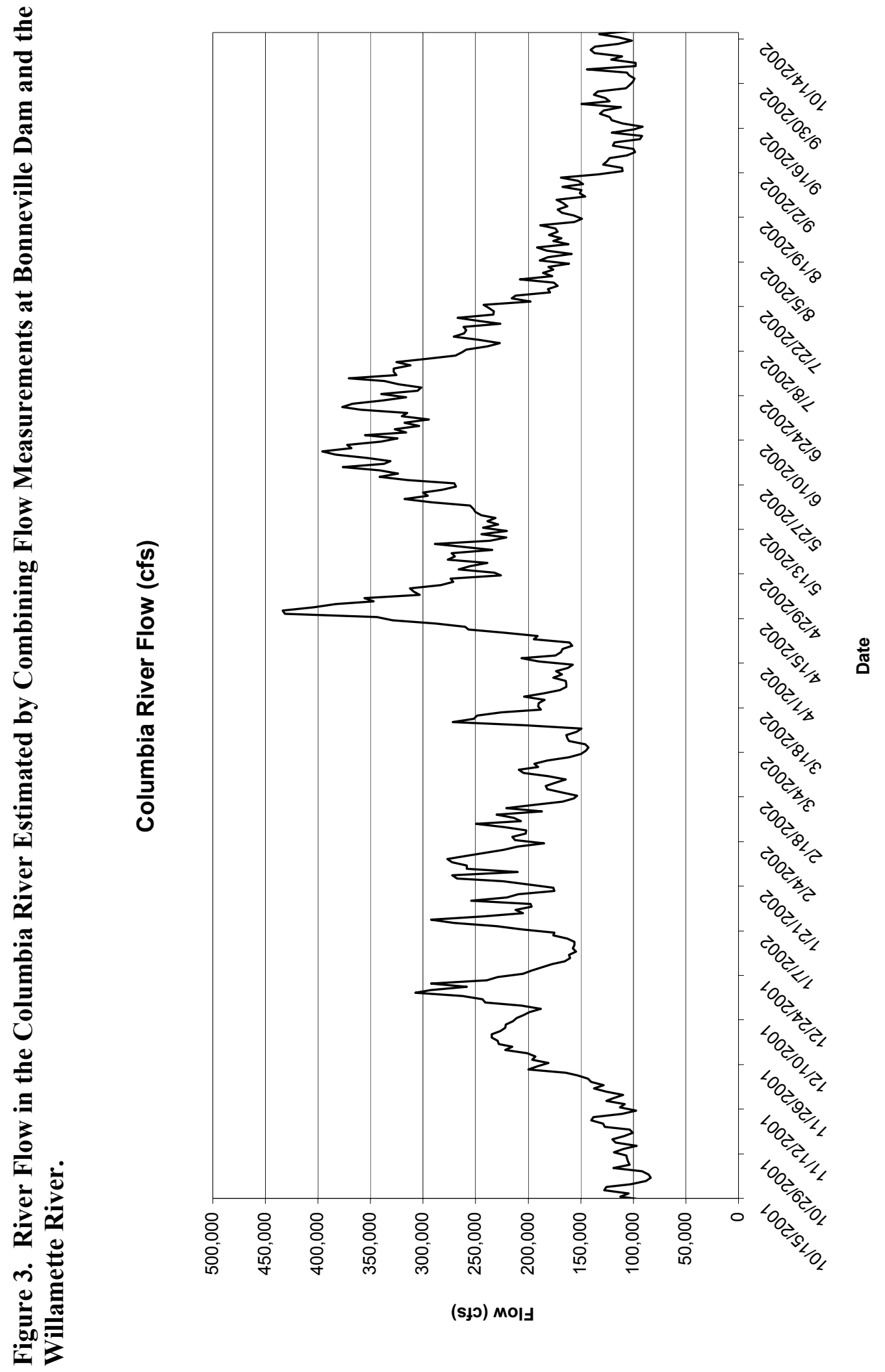
Figure 4. Bottom Salinity from CORIE Mean Salinity Profile Predicted by ELCIRC Model for May 21 and September 1, 2002.

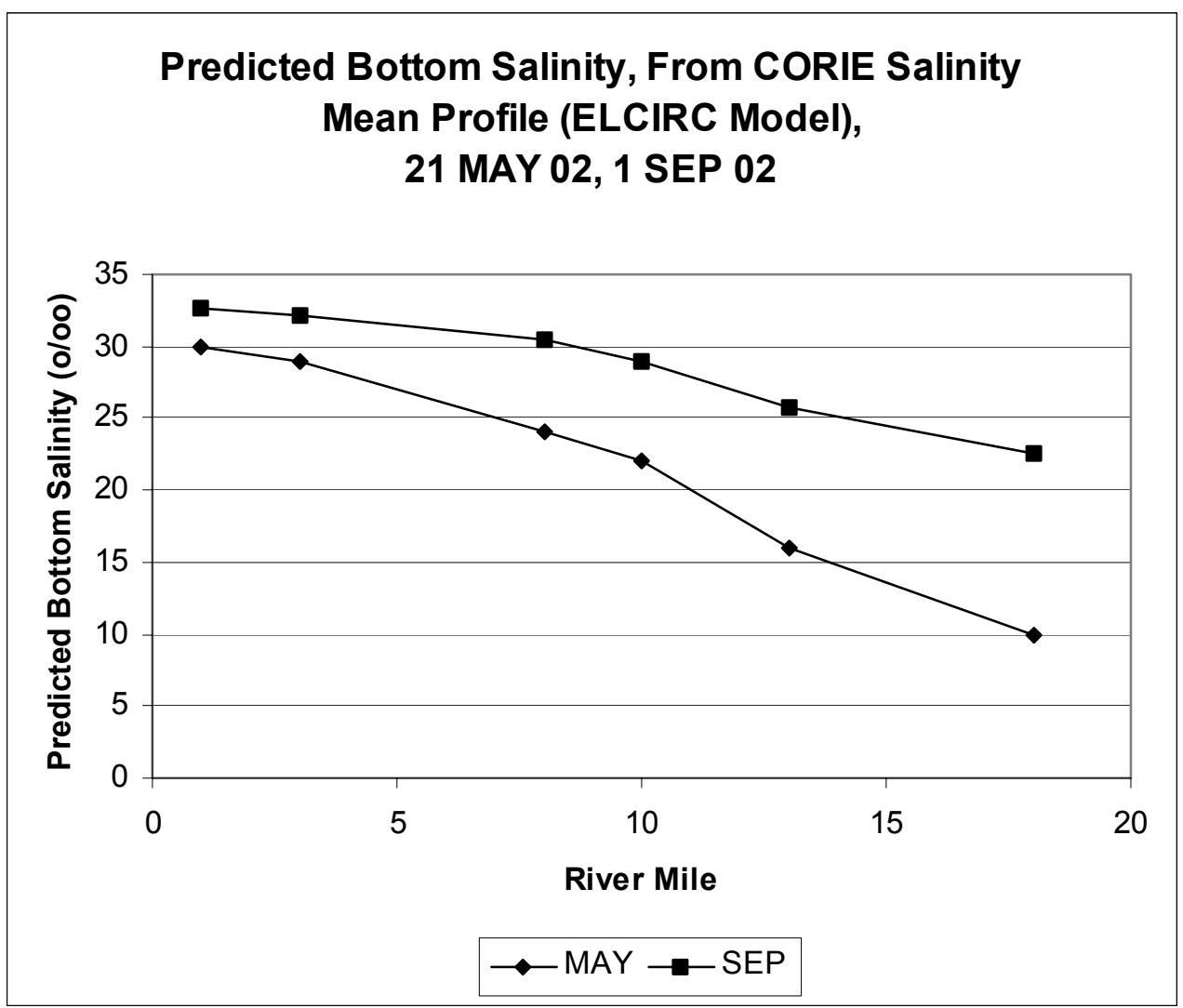


Figure 5. The Entrainment Function from the Grays Harbor Dredge Impact Model with Data from Columbia River Plotted on Same Scale

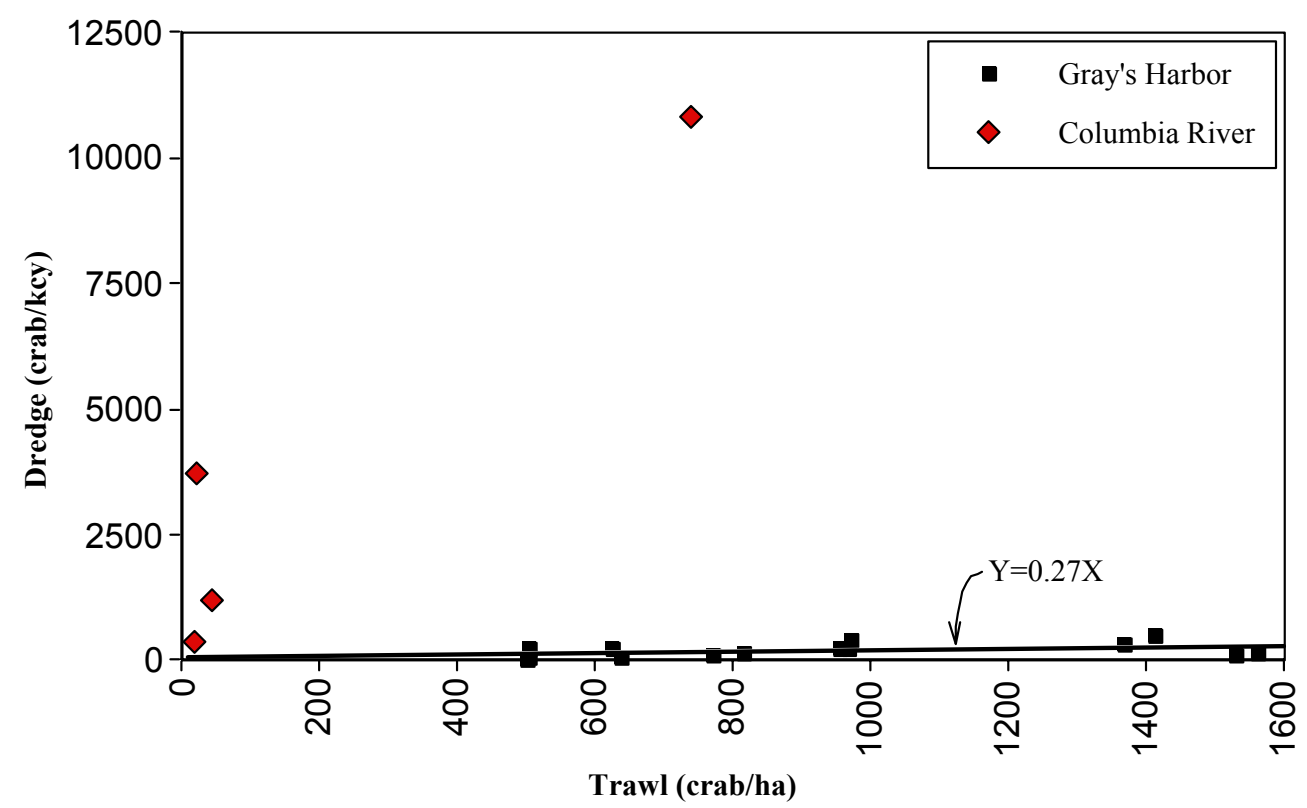

Figure 6. The Structure of a Modified Model for Estimating Entrainment Impacts on Dungeness Crab.

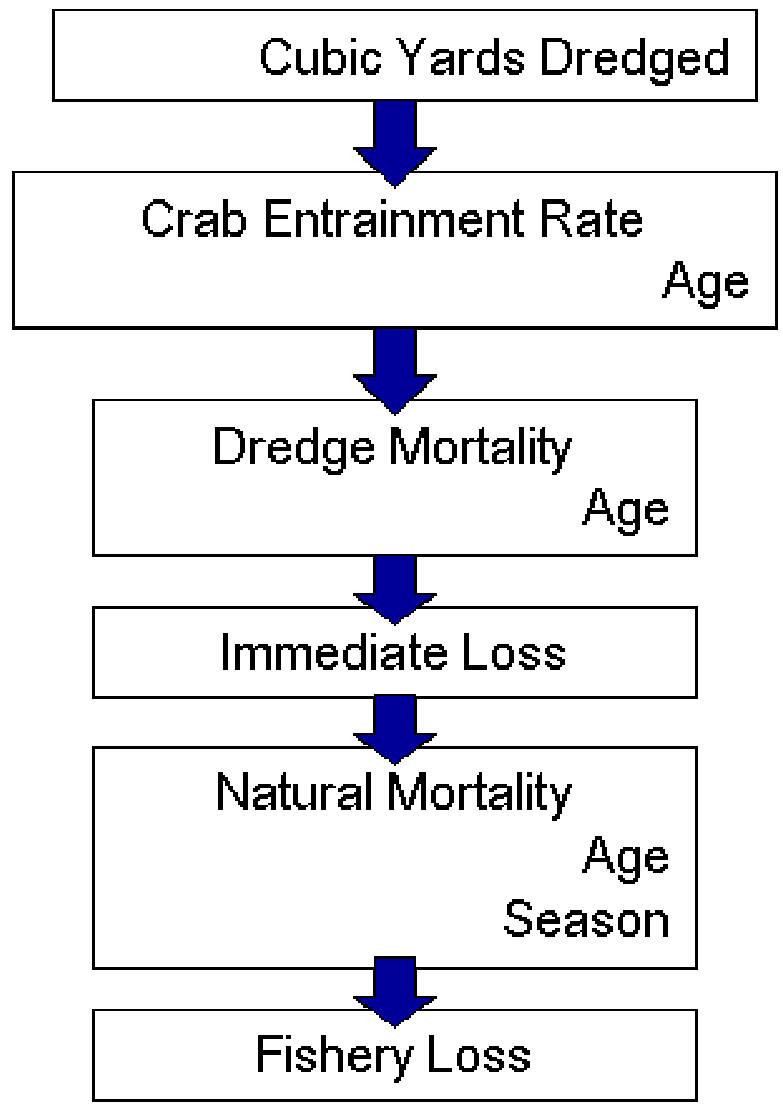




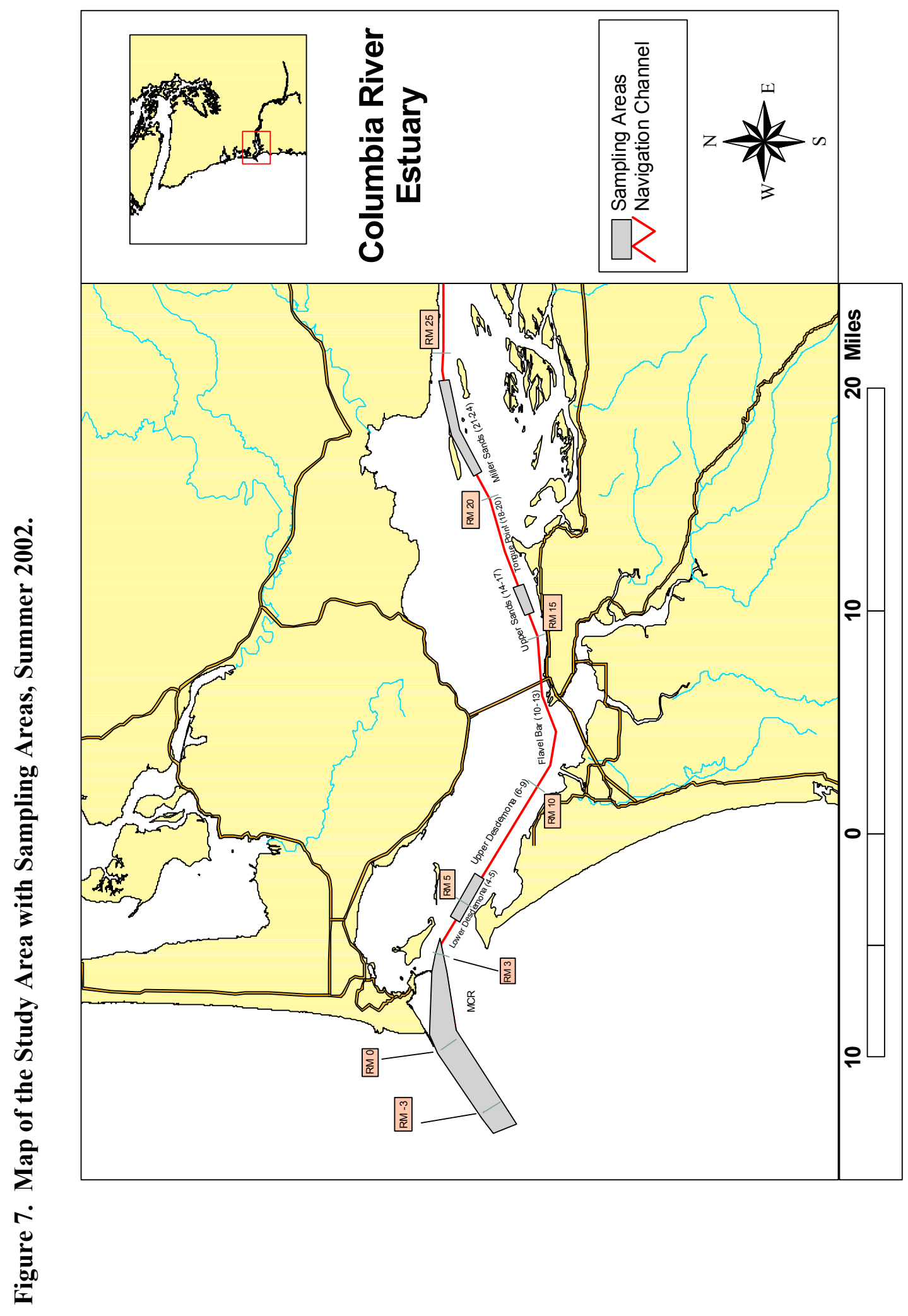

ले 
Figure 8. Diagram of the Piping and Valving on the Corps' Dredge Essayons, Summer 2002.

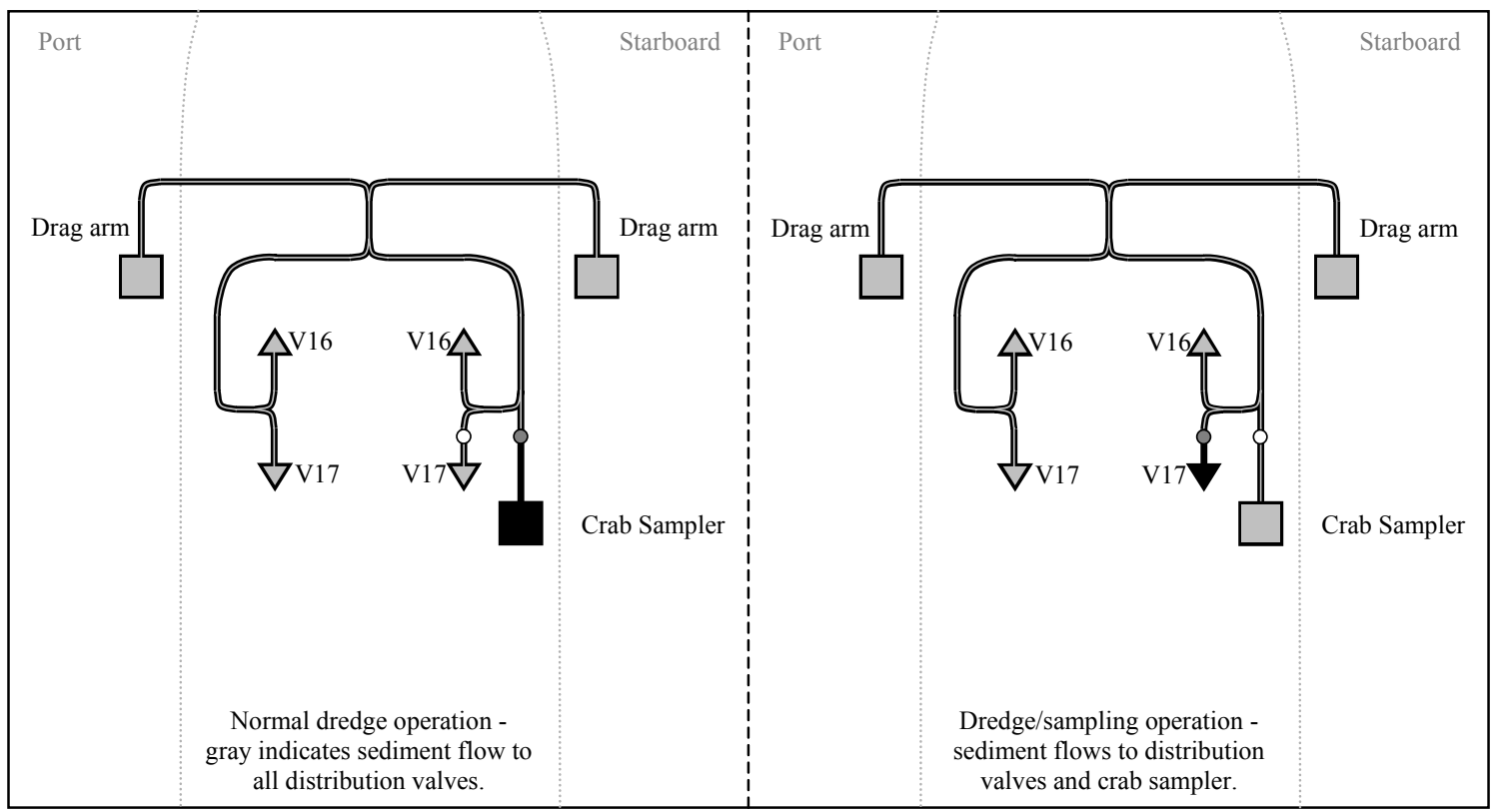


Figure 9. Predicted Crab Density for Six Salinity Intrusion Conditions. From Jay and Smith (1990).

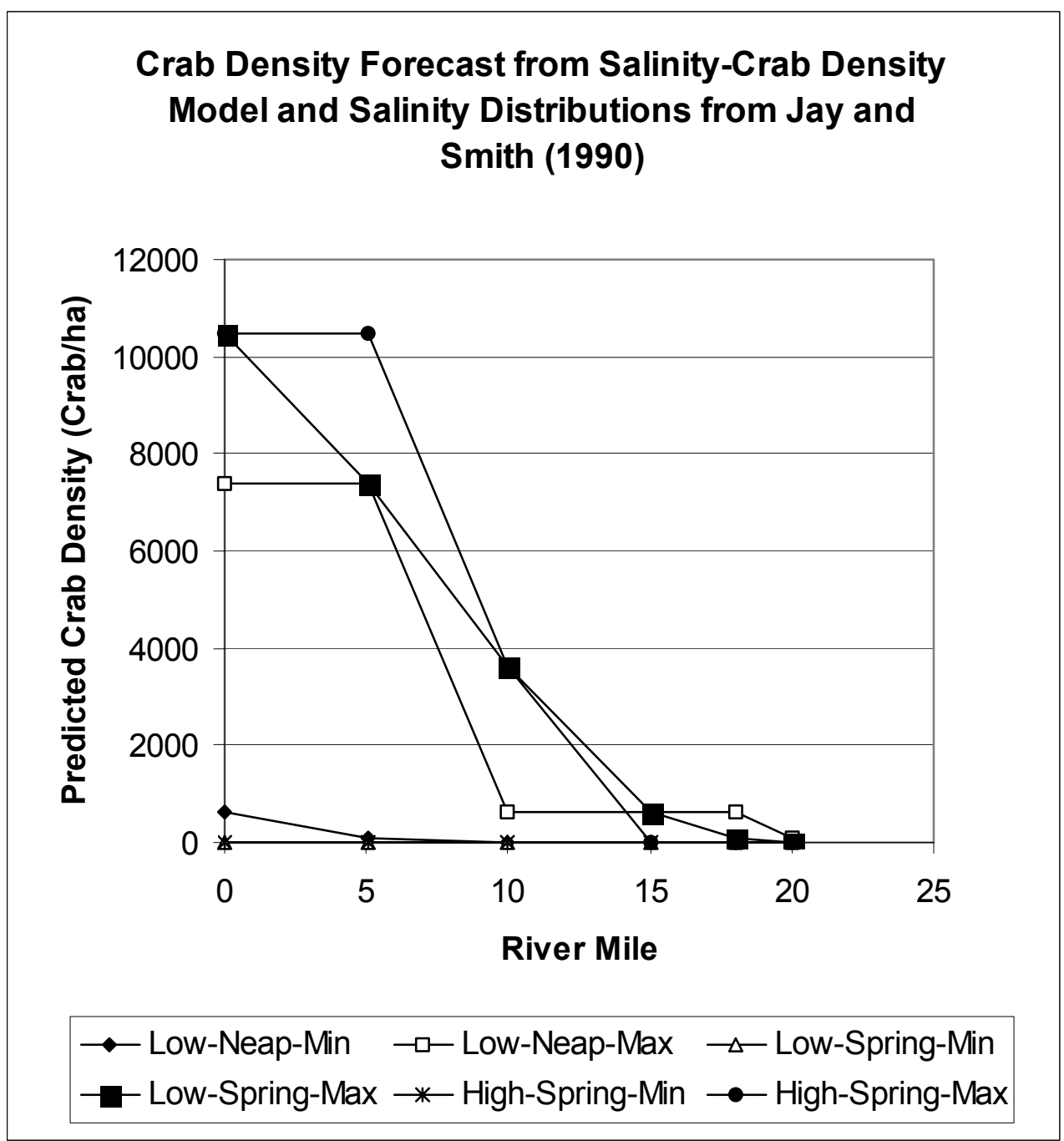


Figure 10. Predicted Crab Density for the Median Low Flow Salinity Intrusion. From Jay and Smith (1990).

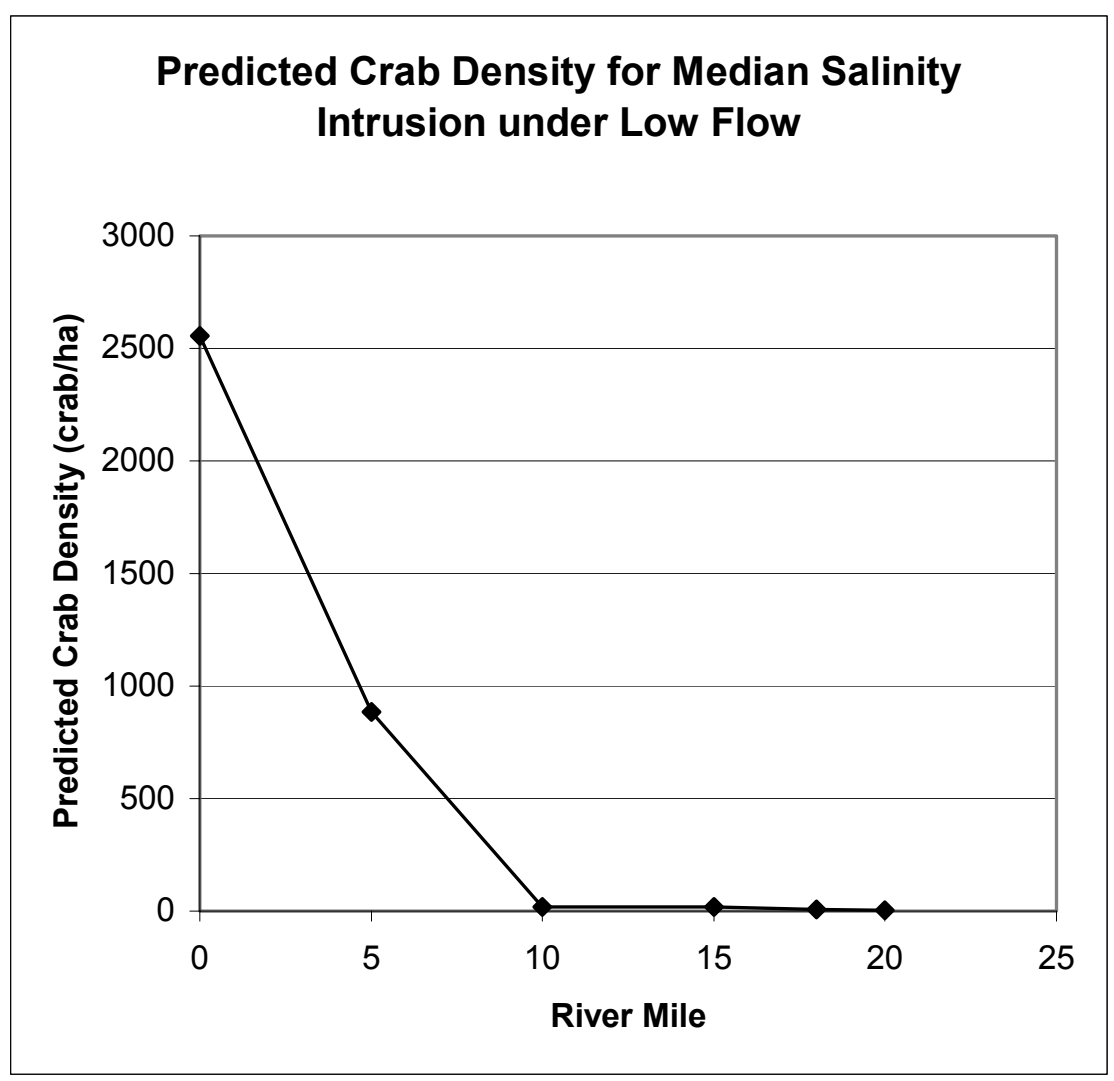


Figure 11. Predicted Crab Density Forecasted with the Salinity Crab Density Model and the ELCIRC Forecasts for Bottom Salinity.

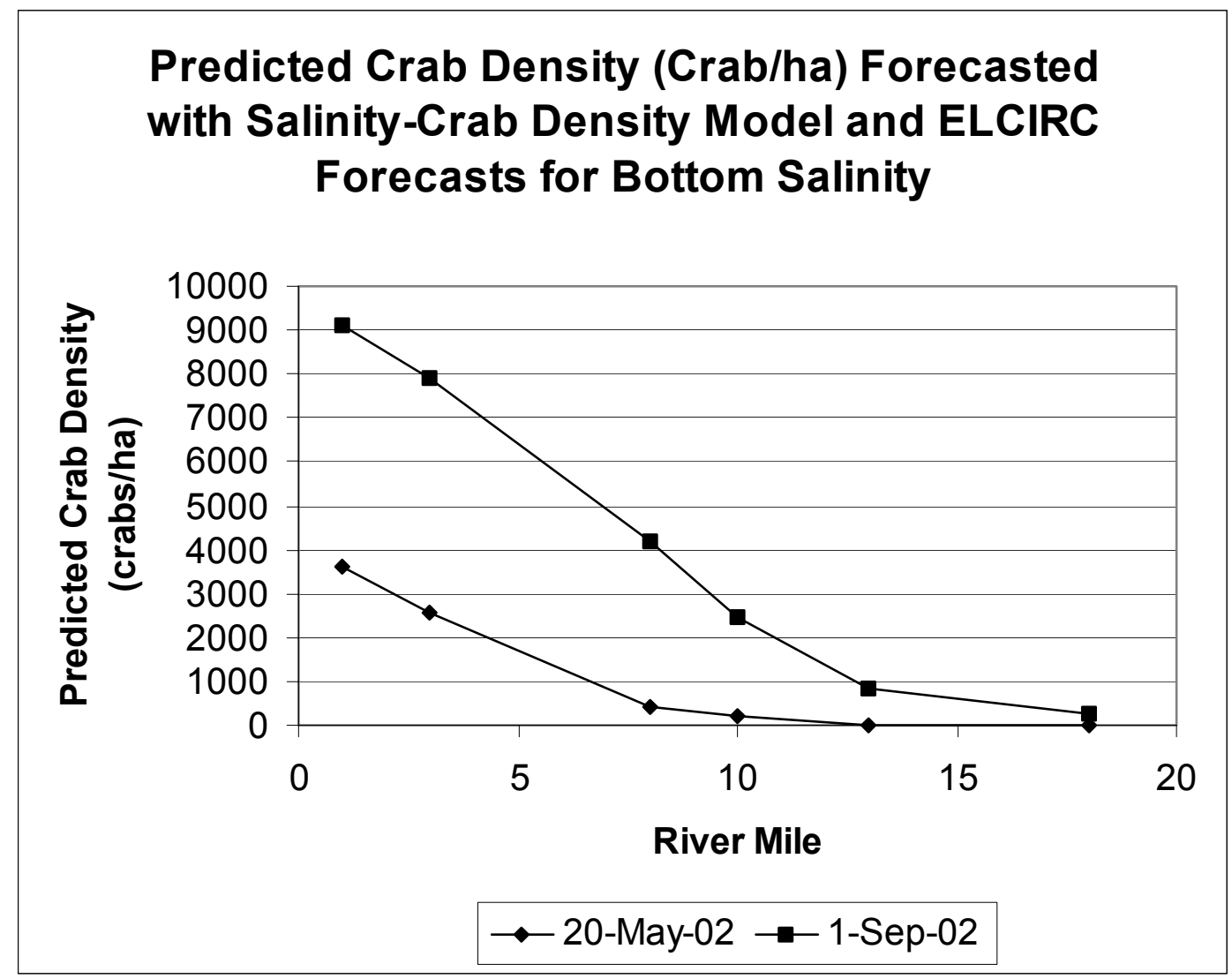




\subsection{TABLES}

Table 1. 1+ Crab Densities by Habitat Type. From Rooper et al. (2002). Densities interpreted from graphs in Rooper et al. (2002) and other data taken from tables in Rooper et al. (2002).

\begin{tabular}{|c|c|c|c|c|}
\hline \multirow[b]{2}{*}{ Bay } & \multirow[b]{2}{*}{ n } & \multicolumn{3}{|c|}{ Mean 1+ Density (crab/ha) } \\
\hline & & \begin{tabular}{|l|} 
Lower \\
Main \\
Channel \\
\end{tabular} & \begin{tabular}{|l|} 
Lower \\
Side \\
Channel \\
\end{tabular} & $\begin{array}{l}\text { Upper } \\
\text { Estuary }\end{array}$ \\
\hline Grays Harbor & 9 & 483 & 1722 & 228 \\
\hline Willapa Bay & 9 & 270 & 772 & 216 \\
\hline Yaquina Bay & 3 & 630 & 830 & 296 \\
\hline Coos Bay & 3 & 571 & 1300 & 695 \\
\hline Mean & & 489 & 1156 & 359 \\
\hline Mean Salinity (o/oo) & & 28.5 & 26.1 & 25.1 \\
\hline Tide Flat $(\%)$ & & 20.7 & 53 & 40.1 \\
\hline
\end{tabular}

Table 2. Isohaline Positions in the Columbia River as a Function of River Flow and Tidal Regime. Data taken from Graphs in Jay and Smith (1990).

\begin{tabular}{|c|c|c|r|r|r|r|r|}
\hline \multicolumn{4}{|c|}{ Conditions } & \multicolumn{5}{c|}{ Isohaline Position (River Mile) } \\
\hline Flow & Tide & Max/Min & $\mathbf{3 0}$ o/oo & $\mathbf{2 5}$ o/oo & $\mathbf{2 0 ~ o / o 0}$ & $\mathbf{1 5}$ o/oo & $\mathbf{1 0}$ o/oo \\
\hline Low Flow & Neap & Minimum & 0 & 3.8 & 5.0 & 5.4 & 6.5 \\
\hline Low Flow & Neap & Maximum & 7.3 & 18.3 & 23.8 & 24.6 & 25.0 \\
\hline Low Flow & Spring & Minimum & 0 & 0 & 0 & 5.4 & 7.1 \\
\hline Low Flow & Spring & Maximum & 11.1 & 14.3 & 17.1 & 18.9 & 20.4 \\
\hline High Flow & Spring & Minimum & 0 & 0 & 0 & 0 & 0 \\
\hline High Flow & Spring & Maximum & 9.6 & 11.8 & 12.9 & 14.6 & 15.0 \\
\hline
\end{tabular}


Table 3. Salinity Intrusion as a Function of River Mile in the Columbia River. Data taken from Graphs in Jay and Smith (1990).

\begin{tabular}{|l|c|l|r|r|r|r|r|}
\hline \multicolumn{4}{|c|}{ Conditions } & \multicolumn{5}{c|}{ Within Isohaline at Position } \\
\hline \multicolumn{1}{|c|}{ Flow } & Tide & Max/Min & RM5 & RM10 & RM15 & RM18 & RM20 \\
\hline Low Flow & Neap & Minimum & 20.0 & 5.0 & 5.0 & 5.0 & 5.0 \\
\hline Low Flow & Neap & Maximum & 32.0 & 25.0 & 25.0 & 25.0 & 20.0 \\
\hline Low Flow & Spring & Minimum & 15.0 & 5.0 & 0.5 & 0.0 & 0.0 \\
\hline Low Flow & Spring & Maximum & 32.0 & 30.0 & 25.0 & 20.0 & 15.0 \\
\hline High Flow & Spring & Minimum & 0.0 & 0.0 & 0.0 & 0.0 & 0.0 \\
\hline High Flow & Spring & Maximum & 33.0 & 30.0 & 10.0 & 0.0 & 0.0 \\
\hline
\end{tabular}

Table 4. Crab Density Determined by Scientific Trawling and Calculated from Dredge Entrainment. The data from Wainwright et al. (1990) are from Grays Harbor, where the trawl and entrainment observations were paired. The data from Larson (1993) are from the Columbia River and the observations were not paired.

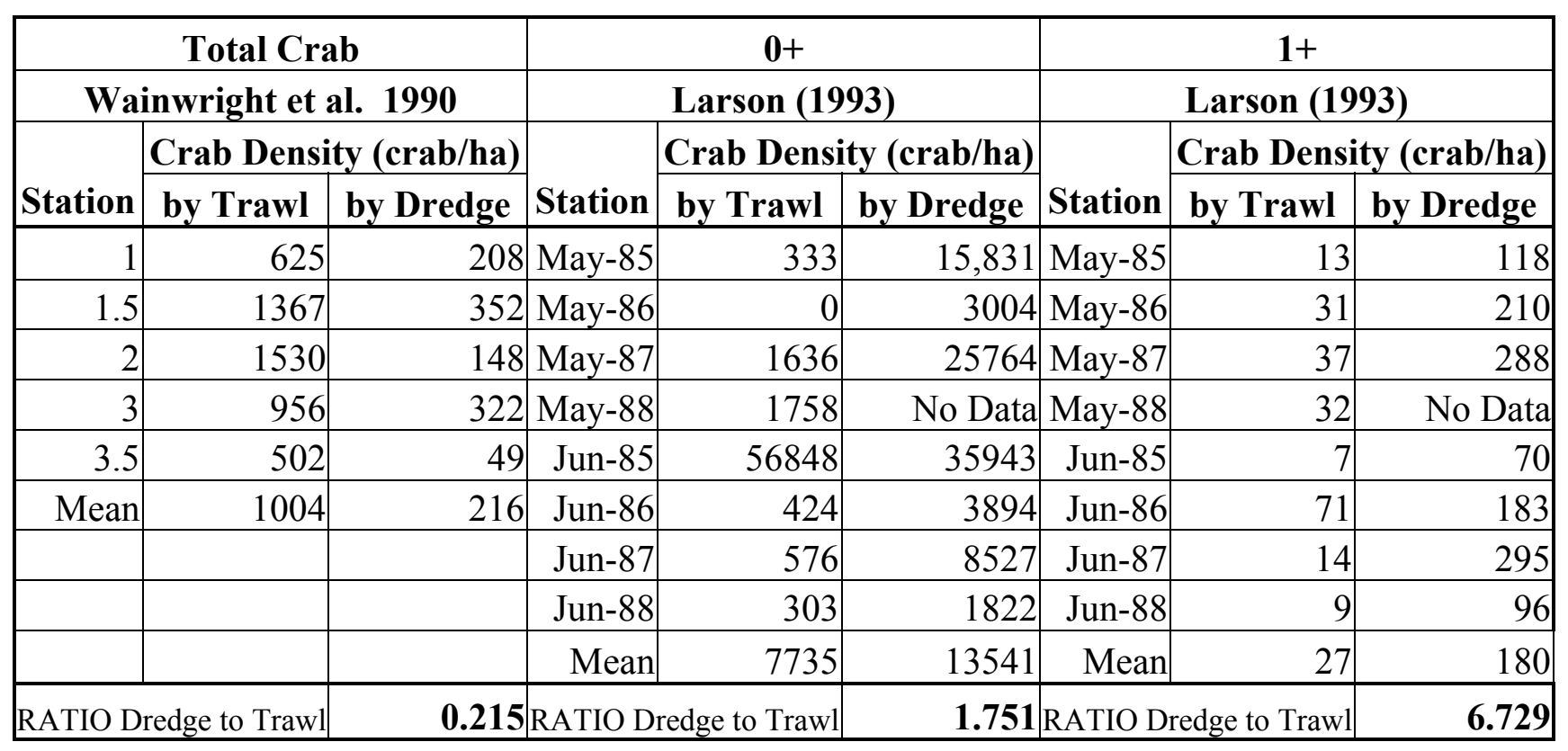


Table 5. Sampling Effort Associated with Various Locations of Crab Entrainment Sampling on the Dredge Essayons During Summer 2002.

\begin{tabular}{|l|c|c|c|r|r|r|}
\hline & & \multicolumn{1}{|c|}{$\begin{array}{c}\text { Total } \\
\text { Dredged } \\
\text { Volume } \\
\text { Location }\end{array}$} & $\begin{array}{c}\text { River Mile } \\
\text { Total } \\
\text { Loads } \\
\text { Dredged }\end{array}$ & $\begin{array}{c}\text { Total } \\
\text { Loads } \\
\text { Sampled }\end{array}$ & $\begin{array}{c}\text { Total } \\
\text { Basket } \\
\text { Samples }\end{array}$ \\
\hline Desdemona Shoals & +4 to +7 & 11 to 15 JUN & 186,737 & 33 & 17 & 169 \\
\hline Desdemona Shoals & +4 to +7 & 17 SEP & 30,012 & 6 & 4 & 12 \\
\hline Upper Sands & +16 & 23 SEP & 54,036 & 9 & 9 & 27 \\
\hline Miller Sands & +21 to +24 & 1 to 8 OCT & 443,563 & 75 & 36 & 140 \\
\hline $\begin{array}{l}\text { Mouth of Columbia } \\
\text { River }\end{array}$ & -3 to +3 & $\begin{array}{c}\text { 8 JU to 15 } \\
\text { OCT }\end{array}$ & $2,763,119$ & 489 & 214 & 643 \\
\hline
\end{tabular}

Table 6. Coefficients of Variation of Different Rates of Basket Samples per Dredge Load. Based on Data of Larson (1993).

\begin{tabular}{|c|c|c|}
\hline Basket & \multicolumn{2}{|c|}{ CV } \\
\cline { 2 - 3 } $\begin{array}{c}\text { Samples } \\
\text { Per } \\
\text { Load }\end{array}$ & $\begin{array}{c}\text { All } \\
\text { Loads }\end{array}$ & $\begin{array}{c}\mathbf{1 / 2} \\
\text { Loads }\end{array}$ \\
\hline 2 & 0.139 & 0.221 \\
\hline 3 & 0.113 & 0.187 \\
\hline 4 & 0.098 & 0.167 \\
\hline 5 & 0.088 & 0.154 \\
\hline 6 & 0.08 & 0.144 \\
\hline 7 & 0.074 & 0.137 \\
\hline 8 & 0.07 & 0.131 \\
\hline 9 & 0.066 & 0.127 \\
\hline 10 & 0.062 & 0.123 \\
\hline
\end{tabular}


Table 7. Coefficients of Variation of Different Rates of Basket Samples per Dredge Load. Based on Data from June 2002. Note: The column for 0+ crab uses all 17 loads of which only 5 detected $0+$ age class; precision calculations based on only the loads with observed crabs yields a CV of 0.114 for 2 basket samples per load.

\begin{tabular}{|c|c|c|c|c|}
\hline Basket & \multicolumn{4}{|c|}{ Age Class } \\
$\begin{array}{c}\text { Samples } \\
\text { per Load }\end{array}$ & $\mathbf{0 +}$ & $\mathbf{1 +}$ & $\mathbf{2 +}$ & $\mathbf{3 +}$ \\
\hline 1 & 0.185 & 0.064 & 0.151 & 0.268 \\
\hline 2 & 0.149 & 0.049 & 0 & 0.24 \\
\hline 3 & 0.135 & 0.043 & 0.086 & 0.23 \\
\hline 4 & 0.127 & 0.04 & 0.076 & 0.224 \\
\hline 5 & 0.122 & 0.038 & 0.07 & 0.221 \\
\hline
\end{tabular}


Table 8. Projected Dredge Volumes for Future Construction Dredging (to 40' and from 40' to 43') Associated With the Columbia River Channel Improvement Project.

\begin{tabular}{|r|c|r|r|r|r|}
\hline \multicolumn{3}{|c|}{ Dredging to 40'} & \multicolumn{3}{|c|}{ Dredging from 40' to 43' } \\
\hline \multicolumn{1}{|c|}{ River Mile } & Location & Volume (cy) & River Mile & Location & Volume (cy) \\
\hline 4 & Lower Desdem. & 94,688 & 4 & Lower Desdem. & 222,412 \\
\hline 5 & & 196,724 & 5 & & 353,916 \\
\hline 6 & Upper Desdem & 66,193 & 6 & Upper Desdem & 0 \\
\hline 7 & & 1,039 & 7 & & 0 \\
\hline 8 & & 52,398 & 8 & & 8,742 \\
\hline 9 & & 62,851 & 9 & & 8,742 \\
\hline 10 & Flavel Bar & 329,296 & 10 & Flavel Bar & 49,732 \\
\hline 11 & & 535,074 & 11 & & 298,900 \\
\hline 12 & & 239,608 & 12 & & 121,292 \\
\hline 13 & & 65,743 & 13 & & 72,425 \\
\hline 14 & Upper Sands & 171,432 & 14 & Upper Sands & 54,585 \\
\hline 15 & & 271,842 & 15 & & 51,945 \\
\hline 16 & & 306,717 & 16 & & 47,557 \\
\hline 17 & & 108,631 & 17 & & 0 \\
\hline 18 & Tongue Point & 174,113 & 18 & Tongue Point & 14,775 \\
\hline 19 & & 162,864 & 19 & & 6,976 \\
\hline 20 & & 127,219 & 20 & & 13,283 \\
\hline Total & & $2,966,432$ & Total & & $1,325,282$ \\
\hline
\end{tabular}

Summary of Planned Construction Volumes

\begin{tabular}{|r|r|r|r|}
\hline \multicolumn{1}{|c|}{ Location } & To 40' & From 40' to 43' & Combined \\
\hline MCR & ND & ND & ND = No Data \\
\hline Desdemona (Upper and Lower) & 473,893 & 593,812 & $1,067,705$ \\
\hline Flavel Bar & $1,169,721$ & 542,349 & $1,712,070$ \\
\hline Upper Sands & 858,622 & 154,087 & $1,012,709$ \\
\hline Tongue Pt & 464,196 & 35,034 & 499,230 \\
\hline Miller Sands & ND & ND & ND \\
\hline
\end{tabular}


Table 9. Projected Volumes During Year 1 and Year 20 Maintenance Dredging Associated with 40-foot Channel Maintenance (No Action Alternative) and the 43foot Alternative (Proposed Plan).

\begin{tabular}{|l|r|r|r|r|}
\hline \multirow{2}{*}{ Location } & \multicolumn{2}{|c|}{$\begin{array}{c}\text { 40-foot Channel } \\
\text { Maintenance } \\
\text { (No Action Alternative) }\end{array}$} & \multicolumn{2}{c|}{$\begin{array}{c}\text { 43-foot Alternative } \\
\text { Maintenance } \\
\text { (Proposed Plan) }\end{array}$} \\
\cline { 2 - 5 } & Year 1 & Year 20 & Year 1 & \multicolumn{1}{c|}{ Year 20 } \\
\hline Desdemona & 40,000 & 40,000 & 60,000 & 40,000 \\
\hline Flavel Bar & 400,000 & 210,000 & 500,000 & 210,000 \\
\hline Upper Sands & 50,000 & 50,000 & 100,000 & 100,000 \\
\hline Tonque Point & 270,000 & 270,000 & 330,000 & 330,000 \\
\hline
\end{tabular}

Table 10. Entrainment Rates from Direct Measurements in Summer 2002.

\begin{tabular}{|l|c|c|c|c|c|}
\hline & \multicolumn{5}{|c|}{ Age Class } \\
\hline Area & $0+$ & $1+$ & $2+$ & $3+$ & All \\
\hline Desdemona June & 0.005 & 0.193 & 0.024 & 0.001 & 0.224 \\
\hline Desdemona Sept & 0.000 & 0.022 & 0.065 & 0.033 & 0.120 \\
\hline Upper Sands & 0.010 & 0.010 & 0.000 & 0.000 & 0.021 \\
\hline Miller Sands & 0.000 & 0.000 & 0.000 & 0.000 & 0.000 \\
\hline
\end{tabular}

Table 11. Summary of Entrainment Rates (R), Entrainment (E), Adult Equivalent Loss (AEL), and Loss to Fishery (LF) with 95\% Confidence Intervals (CI) for the Dredged Volumes Accomplished During the Summer of 2002.

\begin{tabular}{|c|c|c|c|c|c|c|c|c|c|}
\hline Location & $\mathbf{R}$ & $\mathbf{E}$ & $95 \% \mathrm{CI}$ & AEL 2+ & $95 \% \mathrm{CI}$ & AEL 3+ & $95 \% \mathrm{CI}$ & LF & $95 \% \mathrm{CI}$ \\
\hline Desdemona Jun & 0.2236 & 41758.8 & \pm 4099.5 & 6314.1 & \pm 911.9 & 2841.3 & \pm 410.4 & 1193.9 & \pm 189.9 \\
\hline Desdemona Sep & 0.1195 & 3586.2 & +2068.7 & 3023.3 & +1200.1 & 1360.5 & +540.1 & 476.2 & +189.0 \\
\hline Upper Sands & 0.0205 & 1109.5 & \pm 1537.7 & 53.71 & \pm 103.5 & 24.2 & \pm 46.6 & 8.5 & \pm 16.3 \\
\hline Miller Sands & 0.0000 & 0.00 & $\mathrm{n} / \mathrm{a}$ & 0.00 & $\mathrm{n} / \mathrm{a}$ & 0.00 & $\mathrm{n} / \mathrm{a}$ & 0.00 & $\mathrm{n} / \mathrm{a}$ \\
\hline
\end{tabular}


Table 12. Contribution by Age Class to Adult Equivalent Loss (AEL) by Male (M) and Female (F) Crab from Summer 2002 Sampling.

\begin{tabular}{|c|c|c|c|c|c|c|c|c|}
\hline \multirow{2}{*}{\begin{tabular}{|l|} 
\\
Location
\end{tabular}} & \multirow[b]{2}{*}{$\begin{array}{l}\text { Age } \\
\text { Class }\end{array}$} & \multirow[b]{2}{*}{ Sex } & \multirow{2}{*}{\begin{tabular}{|c|}
$\begin{array}{c}\text { Dredged } \\
\text { Volume }\end{array}$ \\
cubic yds \\
\end{tabular}} & \multicolumn{5}{|c|}{ Contribution to AEL by age class } \\
\hline & & & & 0+ & $1+$ & $2+$ & $3+$ & Total \\
\hline \multirow{2}{*}{ Desd June } & $2+$ & $\mathrm{M}$ & 186737 & 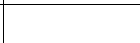 & 173 & 1899 & 158 & 3790 \\
\hline & & $\mathrm{F}$ & & 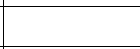 & 173 & 633 & 158 & 2524 \\
\hline \multirow[t]{2}{*}{ Desd June } & $3+$ & M & 186737 & I & 780 & 855 & 71 & 1706 \\
\hline & & $\mathrm{F}$ & & T & 78 & 285 & 71 & 1136 \\
\hline \multirow{2}{*}{ Desd Sep } & $2+$ & $\mathrm{M}$ & 30012 & 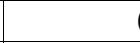 & 3 & 546 & 934 & 1512 \\
\hline & & F & & T & 3 & 546 & 934 & 1512 \\
\hline \multirow[t]{2}{*}{ Desd Sep } & $3+$ & $\mathrm{M}$ & 30012 & 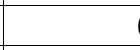 & 12 & 246 & 421 & 680 \\
\hline & & $\mathrm{F}$ & & t & 12 & 246 & 421 & 680 \\
\hline \multirow[t]{2}{*}{ Upper Sands } & $2+$ & $\mathrm{M}$ & 54036 & ( & 26 & 0 & 0 & 27 \\
\hline & & $\mathrm{F}$ & & 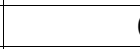 & 26 & 0 & 0 & 27 \\
\hline \multirow[t]{2}{*}{ Upper Sands } & $3+$ & $\mathrm{M}$ & 54036 & T & 12 & 0 & 0 & 12 \\
\hline & & $\mathrm{F}$ & & ( & 12 & 0 & 0 & 12 \\
\hline \multirow[t]{2}{*}{ Miller Sands } & $2+$ & $\mathrm{M}$ & 443563 & 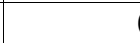 & 0 & 0 & 0 & 0 \\
\hline & & $\mathrm{F}$ & & ( & 0 & 0 & 0 & 0 \\
\hline \multirow[t]{2}{*}{ Miller Sands } & $3+$ & $\mathrm{M}$ & 443563 & T & 0 & 0 & 0 & 0 \\
\hline & & $\mathrm{F}$ & & T & 0 & 0 & 0 & 0 \\
\hline
\end{tabular}


Table 13. Crab AEL and LF Projected for Construction Dredging to 40'.

\begin{tabular}{|c|c|c|c|c|c|c|}
\hline & & & AEL & $95 \%$ CI & $\begin{array}{l}\text { Loss to } \\
\text { Fishery }\end{array}$ & $95 \%$ CI \\
\hline Location & Age Class & Sex & Total & & Total & \\
\hline \multirow[t]{2}{*}{ Desd June } & $2+$ & $\mathrm{M}$ & 12,052 & $\pm 1,741$ & 3,796 & \pm 603 \\
\hline & & $\mathrm{F}$ & 8,026 & \pm 592 & & \\
\hline \multirow[t]{2}{*}{ Desd June } & $3+$ & $\mathrm{M}$ & 5,423 & \pm 783 & 3,796 & \pm 603 \\
\hline & & $\mathrm{F}$ & 3,612 & \pm 522 & & \\
\hline \multirow[t]{2}{*}{ Desd Sep } & $2+$ & $\mathrm{M}$ & 29,909 & $\pm 11,871$ & 9,422 & $\pm 3,739$ \\
\hline & & $\mathrm{F}$ & 29,909 & $\pm 11,871$ & & \\
\hline \multirow[t]{2}{*}{ Desd Sep } & $3+$ & $\mathrm{M}$ & 13,459 & $\pm 5,342$ & 9,422 & $\pm 3,739$ \\
\hline & & $\mathrm{F}$ & 13,459 & $\pm 5,342$ & & \\
\hline \multirow[t]{2}{*}{ Flavel Bar* } & $2+$ & $\mathrm{M}$ & 11,008 & $\pm 1,590$ & 3,467 & $\pm 3,467$ \\
\hline & & $\mathrm{F}$ & 7,331 & $\pm 1,059$ & & \\
\hline \multirow[t]{2}{*}{ Flavel Bar* } & $3+$ & $\mathrm{M}$ & 4,953 & \pm 716 & 3,467 & $\pm 3,467$ \\
\hline & & $\mathrm{F}$ & 3,299 & \pm 477 & & \\
\hline \multirow[t]{2}{*}{ Flavel Bar** } & $2+$ & $\mathrm{M}$ & 27,317 & $\pm 10,842$ & 8,605 & $\pm 3,415$ \\
\hline & & $\mathrm{F}$ & 27,317 & $\pm 10,842$ & & \\
\hline \multirow[t]{2}{*}{ Flavel Bar** } & $3+$ & $\mathrm{M}$ & 12,293 & $\pm 4,879$ & 8,605 & $\pm 3,415$ \\
\hline & & $\mathrm{F}$ & 12,293 & $\pm 4,879$ & & \\
\hline \multirow[t]{2}{*}{ Flavel Bar*** } & $2+$ & $\mathrm{M}$ & 270 & \pm 519 & 85 & \pm 164 \\
\hline & & $\mathrm{F}$ & 270 & \pm 519 & & \\
\hline \multirow[t]{2}{*}{ Flavel Bar*** } & $3+$ & $\mathrm{M}$ & 121 & \pm 234 & 85 & \pm 164 \\
\hline & & $\mathrm{F}$ & 121 & \pm 234 & & \\
\hline \multirow[t]{2}{*}{ Upper Sands } & $2+$ & $\mathrm{M}$ & 77 & \pm 148 & 24 & \pm 46 \\
\hline & & $\mathrm{F}$ & 77 & \pm 148 & & \\
\hline \multirow[t]{2}{*}{ Upper Sands } & $3+$ & $\mathrm{M}$ & 34 & \pm 66 & 24 & \pm 46 \\
\hline & & $\mathrm{F}$ & 34 & \pm 66 & & \\
\hline \multirow[t]{2}{*}{ Tongue Pt! } & $2+$ & $\mathrm{M}$ & 17 & \pm 34 & 6 & \pm 11 \\
\hline & & $\mathrm{F}$ & 17 & \pm 34 & & \\
\hline \multirow[t]{2}{*}{ Tongue Pt! } & $3+$ & $\mathrm{M}$ & 8 & \pm 15 & 6 & \pm 11 \\
\hline & & $\mathrm{F}$ & 8 & \pm 15 & & \\
\hline \multirow[t]{2}{*}{ Tongue Pt!! } & $2+$ & $\mathrm{M}$ & 0 & $\mathrm{n} / \mathrm{a}$ & 0 & $\mathrm{n} / \mathrm{a}$ \\
\hline & & $\mathrm{F}$ & 0 & $\mathrm{n} / \mathrm{a}$ & & \\
\hline \multirow[t]{2}{*}{ Tongue Pt!! } & $3+$ & $\mathrm{M}$ & 0 & $\mathrm{n} / \mathrm{a}$ & 0 & $\mathrm{n} / \mathrm{a}$ \\
\hline & & $\mathrm{F}$ & 0 & $\mathrm{n} / \mathrm{a}$ & & \\
\hline \multirow[t]{2}{*}{ Miller Sands } & $2+$ & $\mathrm{M}$ & 0 & $\mathrm{n} / \mathrm{a}$ & 0 & $\mathrm{n} / \mathrm{a}$ \\
\hline & & $\mathrm{F}$ & 0 & $\mathrm{n} / \mathrm{a}$ & & \\
\hline \multirow[t]{2}{*}{ Miller Sands } & $3+$ & $\mathrm{M}$ & 0 & $\mathrm{n} / \mathrm{a}$ & 0 & $\mathrm{n} / \mathrm{a}$ \\
\hline & & $\mathrm{F}$ & 0 & $\mathrm{n} / \mathrm{a}$ & & \\
\hline \multicolumn{7}{|c|}{ * based on Desdemona JUN entrainment rates } \\
\hline \multicolumn{7}{|c|}{ ** based on Desdemona SEP entrainment rates } \\
\hline \multicolumn{7}{|c|}{ *** based on Upper Sands entrainment rates } \\
\hline \multicolumn{7}{|c|}{ ! based on Upper Sands entrainment rates } \\
\hline \multicolumn{7}{|c|}{ !! based on Miller Sands entrainment rates } \\
\hline
\end{tabular}


Table 14. Crab AEL and LF Projected for Construction Dredging from 40' to 43'.

\begin{tabular}{|c|c|c|c|c|c|c|}
\hline & & & AEL & $95 \%$ CI & $\begin{array}{l}\text { Loss to } \\
\text { Fishery }\end{array}$ & $95 \% \mathrm{CI}$ \\
\hline Location & Age Class & Sex & Total & & Total & \\
\hline \multirow[t]{2}{*}{ Desd June } & $2+$ & $\mathrm{M}$ & 9,618 & $\pm 1,389$ & 3,030 & \pm 482 \\
\hline & & $\mathrm{F}$ & 6,405 & \pm 925 & & \\
\hline \multirow[t]{2}{*}{ Desd June } & $3+$ & $\mathrm{M}$ & 4,328 & \pm 625 & 3,030 & \pm 482 \\
\hline & & $\mathrm{F}$ & 2,882 & \pm 416 & & \\
\hline \multirow[t]{2}{*}{ Desd Sep } & $2+$ & $\mathrm{M}$ & 23,869 & $\pm 9,474$ & 7,519 & $\pm 2,984$ \\
\hline & & $\mathrm{F}$ & 23,869 & $\pm 9,474$ & & \\
\hline \multirow[t]{2}{*}{ Desd Sep } & $3+$ & $\mathrm{M}$ & 10,741 & $\pm 4,263$ & 7,519 & $\pm 2,984$ \\
\hline & & $\mathrm{F}$ & 10,741 & $\pm 4,263$ & & \\
\hline \multirow[t]{2}{*}{ Flavel Bar* } & $2+$ & $\mathrm{M}$ & 23,741 & $\pm 3,429$ & 7,478 & $\pm 1,189$ \\
\hline & & $\mathrm{F}$ & 15,811 & $\pm 2,284$ & & \\
\hline \multirow[t]{2}{*}{ Flavel Bar* } & $3+$ & $\mathrm{M}$ & 10,683 & $\pm 1,543$ & 7,478 & $\pm 1,189$ \\
\hline & & $\mathrm{F}$ & 7,115 & $\pm 1,028$ & & \\
\hline \multirow[t]{2}{*}{ Flavel Bar** } & $2+$ & $\mathrm{M}$ & 58,917 & $\pm 23,384$ & 18,559 & $\pm 7,366$ \\
\hline & & $\mathrm{F}$ & 58,917 & $\pm 23,384$ & & \\
\hline \multirow[t]{2}{*}{ Flavel Bar** } & $3+$ & $\mathrm{M}$ & 26,513 & $\pm 10,523$ & 18,559 & $\pm 7,366$ \\
\hline & & $\mathrm{F}$ & 26,513 & $\pm 10,523$ & & \\
\hline \multirow[t]{2}{*}{ Flavel Bar*** } & $2+$ & $\mathrm{M}$ & 581 & $\pm 1,120$ & 183 & \pm 353 \\
\hline & & $\mathrm{F}$ & 581 & $\pm 1,120$ & & \\
\hline \multirow[t]{2}{*}{ Flavel Bar*** } & $3+$ & $\mathrm{M}$ & 262 & \pm 504 & 183 & \pm 353 \\
\hline & & $\mathrm{F}$ & 262 & \pm 504 & & \\
\hline \multirow[t]{2}{*}{ Upper Sands } & $2+$ & $\mathrm{M}$ & 427 & \pm 822 & 134 & \pm 259 \\
\hline & & $\mathrm{F}$ & 427 & \pm 822 & & \\
\hline \multirow[t]{2}{*}{ Upper Sands } & $3+$ & $\mathrm{M}$ & 192 & \pm 370 & 134 & \pm 259 \\
\hline & & $\mathrm{F}$ & 192 & \pm 370 & & \\
\hline \multirow[t]{2}{*}{ Tongue Pt! } & $2+$ & $\mathrm{M}$ & 231 & \pm 444 & 73 & \pm 140 \\
\hline & & $\mathrm{F}$ & 231 & +444 & & \\
\hline \multirow[t]{2}{*}{ Tongue Pt! } & $3+$ & $\mathrm{M}$ & 104 & \pm 200 & 73 & \pm 140 \\
\hline & & $\mathrm{F}$ & 104 & \pm 200 & & \\
\hline \multirow[t]{2}{*}{ Tongue Pt!! } & $2+$ & $\mathrm{M}$ & 0 & $\mathrm{n} / \mathrm{a}$ & 0 & $\mathrm{n} / \mathrm{a}$ \\
\hline & & $\mathrm{F}$ & 0 & $\mathrm{n} / \mathrm{a}$ & & \\
\hline \multirow[t]{2}{*}{ Tongue Pt!! } & $3+$ & $\mathrm{M}$ & 0 & $\mathrm{n} / \mathrm{a}$ & 0 & $\mathrm{n} / \mathrm{a}$ \\
\hline & & $\mathrm{F}$ & 0 & $\mathrm{n} / \mathrm{a}$ & & \\
\hline \multirow[t]{2}{*}{ Miller Sands } & $2+$ & $\mathrm{M}$ & 0 & $\mathrm{n} / \mathrm{a}$ & 0 & $\mathrm{n} / \mathrm{a}$ \\
\hline & & $\mathrm{F}$ & 0 & $\mathrm{n} / \mathrm{a}$ & & \\
\hline \multirow[t]{2}{*}{ Miller Sands } & $3+$ & $\mathrm{M}$ & 0 & $\mathrm{n} / \mathrm{a}$ & 0 & $\mathrm{n} / \mathrm{a}$ \\
\hline & & $\mathrm{F}$ & 0 & $\mathrm{n} / \mathrm{a}$ & & \\
\hline \multicolumn{7}{|c|}{ * based on Desdemona JUN entrainment rates } \\
\hline \multicolumn{7}{|c|}{ ** based on Desdemona SEP entrainment rates } \\
\hline \multicolumn{7}{|c|}{ *** based on Upper Sands entrainment rates } \\
\hline \multicolumn{7}{|c|}{ ! based on Upper Sands entrainment rates } \\
\hline \multicolumn{7}{|c|}{ !! based on Miller Sands entrainment rates } \\
\hline
\end{tabular}


Table 15. Summary of AEL at 2+ and Losses to Fishery For Construction Dredging Under Worst- and Best-Case Assumptions.

\begin{tabular}{|c|c|c|c|c|}
\hline \multirow[b]{2}{*}{ Project Location } & \multicolumn{2}{|c|}{ AEL at $2+$ Under Assumptions } & \multicolumn{2}{|c|}{$\begin{array}{c}\text { Loss to Fishery Under } \\
\text { Assumptions }\end{array}$} \\
\hline & Worst-case & Best-case & Worst-case & Best-case \\
\hline \multicolumn{5}{|c|}{ Dredging to $40^{\prime}$} \\
\hline Desdemona & 59,818 & 20,078 & 9,422 & 3,796 \\
\hline Flavel & 54,634 & 540 & 8,605 & 85 \\
\hline Upper Sands & 154 & 154 & 24 & 24 \\
\hline Tongue Point & 34 & 0 & 6 & 0 \\
\hline Total & 114,640 & 20,772 & 18,057 & 3,905 \\
\hline \multicolumn{5}{|c|}{ Dredging from $40^{\prime}$ to $43^{\prime}$} \\
\hline Desdemona & 47,738 & 16,023 & 7,519 & 3,030 \\
\hline Flavel & 117,834 & 1,162 & 18,559 & 183 \\
\hline Upper Sands & 854 & 854 & 134 & 134 \\
\hline Tongue Point & 462 & 0 & 73 & 0 \\
\hline Total & 166,888 & 18,039 & 26,285 & $\mathbf{3 , 3 4 7}$ \\
\hline \multicolumn{5}{|c|}{ Total Dredging Volume } \\
\hline OVERALL & 281,528 & 38,811 & 44,342 & 7,252 \\
\hline
\end{tabular}

Table 16. Summary of AEL at 2+ and Losses to Fishery For Maintenance Dredging in Year 1 and Year 20 Under Worst-Case Assumptions for Both the "No Action Alternative" and the Proposed Project.

\begin{tabular}{|c|c|c|c|c|}
\hline \multirow{2}{*}{$\begin{array}{l}\text { Project } \\
\text { Location }\end{array}$} & \multicolumn{2}{|c|}{ AEL at $2+$ Under Assumptions } & \multicolumn{2}{|c|}{$\begin{array}{c}\text { Loss to Fishery Under } \\
\text { Assumptions }\end{array}$} \\
\hline & Year 1 & Year 20 & Year 1 & Year 20 \\
\hline \multicolumn{5}{|c|}{ 40-foot Channel Maintenance (No Action Alternative) } \\
\hline Desdemona & 4,030 & 4,030 & 635 & 635 \\
\hline Flavel & 40,295 & 21,155 & 6,346 & 3,332 \\
\hline Upper Sands & 50 & 50 & 8 & 8 \\
\hline Tongue Point & 268 & 268 & 42 & 42 \\
\hline Total & 44,643 & 25,503 & 7,031 & 4,017 \\
\hline \multicolumn{5}{|c|}{ 43-foot Alternative Maintenance (Proposed Project) } \\
\hline Desdemona & 6,044 & 4,030 & 952 & 635 \\
\hline Flavel & 50,369 & 21,155 & 7,933 & 3,332 \\
\hline Upper Sands & 99 & 99 & 16 & 16 \\
\hline Tongue Point & 328 & 328 & 52 & 52 \\
\hline Total & 56,840 & 25,612 & 8,953 & 4,035 \\
\hline
\end{tabular}


Table 17. Entrainment Rates by Location and the Percentage of Salinity Observations More Than 32 o/oo and Less Than 16 o/oo. Note: 0.001 has been added to rates to enable logarithmic transformation before regression.

\begin{tabular}{|c|c|c|c|c|c|}
\hline \multirow[b]{2}{*}{ Location } & \multicolumn{3}{|c|}{ Entrainment Rate (crab/cy) } & \multicolumn{2}{|c|}{$\%$ of Salinity Observations } \\
\hline & Age 1+ & Age 2+3+ & All Ages & $>32$ o/oo & $<16$ o/oo \\
\hline Desdemona JUN & 0.193 & 0.025 & 0.224 & 38 & 16 \\
\hline Desdemona SEP & 0.022 & 0.098 & 0.121 & 83 & 0 \\
\hline Upper Sands & 0.01 & 0.001 & 0.021 & 0 & 67 \\
\hline Miller Sands & 0.001 & 0.001 & 0.001 & 0 & 100 \\
\hline MCR & 0.014 & 0.042 & 0.057 & 96 & 1 \\
\hline
\end{tabular}

Table 18. Results of Regression Analysis Between the Natural Logarithm of the Entrainment Rates and Percentage of Salinity Observations Above 32 o/oo and Below 16 o/oo. Regressions with asterisk are significant.

\begin{tabular}{|c|c|c|c|}
\hline \multirow[b]{2}{*}{ Salinity } & \multicolumn{3}{|c|}{ Entrainment Rate } \\
\hline & All Ages & Age 1+ & Age 2+\& 3+ \\
\hline \multirow[t]{2}{*}{$\%>32$ o/00 } & $\mathrm{p}=0.25$ & $\mathrm{p}=0.51$ & $\mathrm{p}=0.02^{*}$ \\
\hline & & & $\left(r^{2}=0.81\right)$ \\
\hline \multirow[t]{2}{*}{$\%<16$ o/oo } & $\mathrm{p}=0.03 *$ & $\mathrm{p}=0.15$ & $\mathrm{p}=0.01 *$ \\
\hline & $\left(r^{2}=0.86\right)$ & & $\left(r^{2}=0.91\right)$ \\
\hline
\end{tabular}

